\title{
Determination of crack growth for 6082-T6 Aluminium subjected to periodic single and block overloads and underloads using a two dimensional finite element model.
}

\author{
A. A. Aguilar Espinosa, N. A. Fellows ${ }^{*}$, J. F. Durodola and L. J. Fellows \\ Department of Mechanical Engineering and Mathematical Sciences, Faculty of \\ Design, Technology and the Environment, Oxford Brookes University, Wheatley \\ Campus, Wheatley, Oxford, OX33 1HX, UK.
}

\begin{abstract}
The estimation of crack growth under variable amplitude loading is complex due to interaction effects such as plasticity, crack tip blunting, residual stresses, crack tip closure and crack tip branching. Crack closure has been identified to be one of the main interaction effects. In order to study the effect of crack closure the authors have previously carried out experimental testing to obtain more accurate measurements of crack opening and closure $(1,2)$. They have also developed two dimensional plane stress Finite Element models utilising high mesh density whilst maintaining the ability to measure crack growth over long crack lengths (3). This initial work has been extended in this paper to examine the effects of single and block overloads and random spectrum loading on crack growth. The crack length distance that is affected by overloads and underloads measured experimentally and predicted numerically are shown to be very close when using cyclic hardening material properties and kinematic hardening. In addition the comparison of experimental and numerical crack growth versus crack length graphs shows good correlation of the crack growth acceleration and retardation after the applied overload which has not been seen previously. These comparisons seem to be a very useful tool to validate numerical models.
\end{abstract}

KEY WORDS: fatigue; crack growth; finite element, periodic loading; crack closure; overloads

\section{Introduction}

It is generally well recognised that there are interaction effects that modify the fatigue life of components when subject to variable amplitude loading. A key effect of the interactions on fatigue life is crack growth acceleration and retardation. There is though some debate about which interactions cause crack retardation and acceleration and several hypotheses have been proposed as a source of these phenomena. There have been several reviews about load interactions on fatigue crack growth (4-10) which suggest that the principal reasons are: crack closure (plasticity, roughness and oxide), residual stresses, crack tip blunting, crack tip sharpening, crack tip branching, strain hardening, crack deflexion, and change in rate of damage accumulation in the reversed plastic zone ahead of the crack tip. All these interaction mechanisms depend on stress/strain conditions, material quality, load type, environment and other specific conditions that depend on the application. Also some mechanisms are not totally independent of each other (5).

\footnotetext{
* Author to whom correspondence should be addressed: N. A. Fellows. E-mail: nafellows@brookes.ac.uk
} 
Until now, no particular retardation/acceleration mechanism has been accepted as a unified approach by the research community. Several theories have been developed to explain load interactions; these include crack tip blunting, compressive residual stresses at the crack tip and crack closure effects (11). The crack closure concept has been accepted as a major mechanism by a significant number of workers (12-27).

For more than 40 years the concept of crack closure has been investigated for plane stress and plane strain conditions in order to estimate fatigue crack growth rates for constant and variable amplitude loading with the aim of developing quantitative models for the prediction of life in cyclically loaded structures. There has been some good experimental correlation using Elber's modified equation (12) but the results have not been conclusive. One of the reasons for this may be that accurate measurement of the point at which the crack opens and shuts is difficult $(8,9)$. Khalil et. al. $(26,28)$ employed a technique to measure crack opening and closure using an optical microscope with a magnification of 900x. Due to the limited amount of data available on the effect of single, block and periodic overloads/underloads the authors $(1,2)$ carried out a series of fatigue tests on SENB4 specimens using a similar technique using magnifications from 50x to 950x.

Another method employed to verify crack closure has been the use of numerical models. One of the first studies was made by Ohji et al. (29). A FEM model was used to study the crack growth from notches under simple variable amplitude and biaxial loadings $(16,29)$. At about the same time, Newman published the results of his independent investigations $(14,30)$. Work was continued in this area by several authors $(20,31-33)$. The majority of the numerical work carried out though has been related to constant amplitude loading, although some cases of low-high, high-low and single overloads have been carried out $(27,34)$. Borrego et al. (34) for instance applied hi-low load blocks to $\mathrm{M}(\mathrm{T})$ specimens. They found that the type of constraint and material model were key factors in correctly representing the plastic deformation that occurs behind the crack tip. Another paper has also looked at the effect of overload spacing on aluminium 2024-T35 (35). From the literature though it is apparent that there is still the need for more numerical work relating to long cracks and variable amplitude loading (27). 77

To enable long cracks to be analysed, whilst utilising a small crack edge element size, the authors have developed a two dimensional FE model that utilises mesh refinement and the restart capability in ABAQUS (3). This has enabled crack opening loads to be measured for a crack growth of $4 \mathrm{~mm}$ using a minimum element size of $3.9 \mu \mathrm{m}$. This paper compares the results from this model with the results obtained from experimental testing of single, block and periodic overloads/underloads $(1,2)$ to examine how well the model can predict crack growth and crack growth acceleration and deceleration due to these load types. There is shown to be strong correlation in terms of crack acceleration and retardation after overloads/underloads, which supports the theory of crack closure as the main crack growth mechanism, but there are clearly other factors at play as indicated by the load range sensitivity of the crack growth.

\section{Experimental Procedure}

\subsection{Material}


Aluminium alloy 6082 T6 (HE30TF) was used in this research, and in previous research by the Authors (2), as there is limited fatigue crack growth data of series 6000 aluminium and because it is has been applied broadly in load bearing applications such as structural frames and bridges.

\subsection{Material properties characterisation}

The material properties were obtained experimentally by carrying out monotonic experimental tensile tests. The stress-strain curve tests were carried out according to British Standard BS EN 10002-1 (36) . Three tensile tests were carried out from the same batch of material giving an average yield stress, elastic modulus and Poisson's ratio of $248 \mathrm{MPa}, 70 \mathrm{GPa}$ and 0.33 . All the values corresponded well with those found from data tables for this material (37). The material properties for 6082 Aluminium alloy, found in the literature, are presented in Table 1.

\section{Table 1}

Mechanical properties of 6082-T6 aluminium alloy $(2,38)$

\begin{tabular}{|l|l|l|}
\hline Property & Units & Value \\
\hline Yield strength & $\mathrm{MPa}$ & 248 \\
\hline Elastic Modulus & $\mathrm{GPa}$ & 70 \\
\hline Poisson's ratio & & 0.33 \\
\hline Elongation & $\%$ & 9 \\
\hline Cyclic hardening exponent & & 0.064 \\
\hline Cyclic hardening coefficient & $\mathrm{MPa}$ & 443 \\
\hline Fatigue strength exponent & & 0.0695 \\
\hline Fatigue strength coefficient & $\mathrm{MPa}$ & 485 \\
\hline Fatigue ductility exponent & & -0.827 \\
\hline Fatigue ductility coefficient & & 0.773 \\
\hline
\end{tabular}

\section{3 Specimens}

To manufacture the Four-point bending specimens (SENB4) used in this work, and previously by the authors (2), rectangular extruded bars with nominal dimensions $\mathrm{B}=9.52 \mathrm{~mm}, \mathrm{~W}=15.875 \mathrm{~mm}$ were cut to length $\mathrm{L}=200 \mathrm{~mm}$. In order to induce crack propagation a notch was cut into one edge of the specimens; as illustrated in Fig. 1.

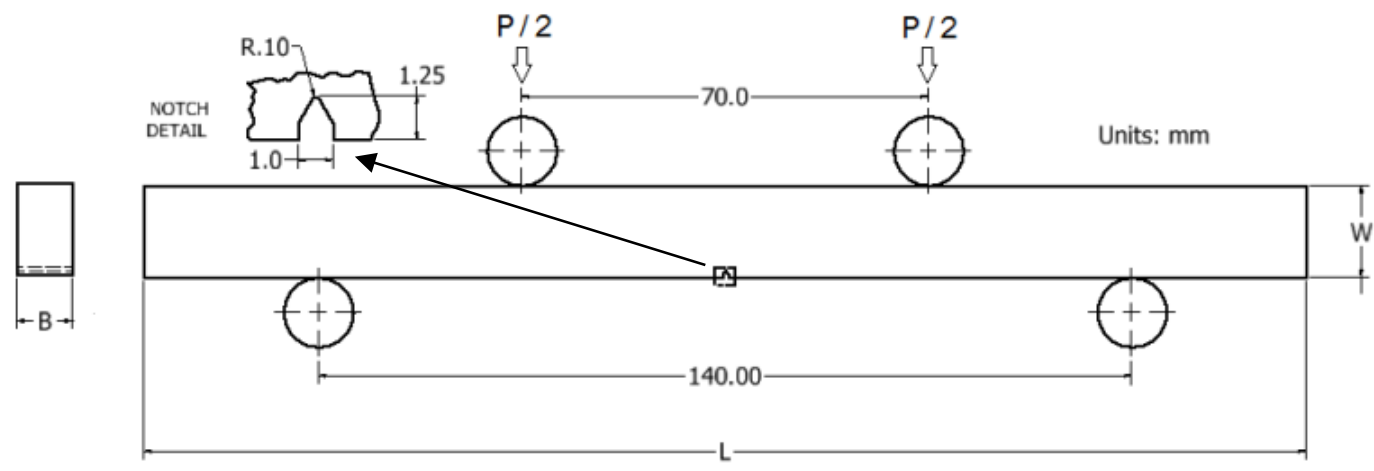

Fig 1. Schematic of Test Configuration, $\mathrm{P}=1.75 \mathrm{kN}$ (Note: actual rig can apply negative as well as positive loads (1)) 


\subsection{Testing Machine}

All tests were carried out with a ESH $25 \mathrm{OkN}$ servo-hydraulic machine using a specially built four point bending rig (1), which has the ability to apply positive and negative loading. Each specimen was tested using load control with a sinusoidal loading of frequency $15 \mathrm{~Hz}$. All experiments were tested at room temperature which varied between $20-25^{\circ} \mathrm{C}$. The machine was NAMAS calibrated.

\subsection{Test matrix}

A range of constant amplitude mode I fatigue tests using SENB4 specimens were carried out to find the Paris (39) and Elber (12) constants for crack growth prediction (2).

In addition thirty-six specimens were used such that twelve different load cases could be analysed according to the test matrix shown in Table 2 .

\section{Table 2}

Experimental Load Cases

\begin{tabular}{|c|c|c|c|}
\hline $\begin{array}{l}\text { LOAD } \\
\text { CASE }\end{array}$ & LOAD SHAPE & LOAD CHARACTERISTICS & $\begin{array}{c}\text { DISTANCE AT } \\
\text { WHICH } \\
\text { OVERLOAD WAS } \\
\text { APPLIED }\end{array}$ \\
\hline $1 \mathrm{a}$ & \multirow{3}{*}{ MMnWhMmM } & $\begin{array}{l}\text { Constant amplitude load: } 1.75 \mathrm{kN} \\
\text { Single overload: } 3 \mathrm{kN}\end{array}$ & 3.25 and $5.25 \mathrm{~mm}$ \\
\hline $1 b$ & & $\begin{array}{l}\text { Constant amplitude load: } 1.75 \mathrm{kN} \\
\text { Single overload: } 3 \mathrm{kN}\end{array}$ & Every $0.5 \mathrm{~mm}$ \\
\hline $1 \mathrm{c}$ & & $\begin{array}{l}\text { Constant amplitude load: } 1.75 \mathrm{kN} \\
\text { Single overload: } 3 \mathrm{kN}\end{array}$ & Every $0.25 \mathrm{~mm}$ \\
\hline $2 a$ & \multirow{3}{*}{ munn Munm } & $\begin{array}{l}\text { Constant amplitude load: } 1.75 \mathrm{kN} \\
\text { Single overload: } 3 \mathrm{kN} \\
\text { Single underload: }-3 \mathrm{kN}\end{array}$ & 3.25 and $5.25 \mathrm{~mm}$ \\
\hline $2 b$ & & $\begin{array}{l}\text { Constant amplitude load: } 1.75 \mathrm{kN} \\
\text { Single overload: } 3 \mathrm{kN} \\
\text { Single underload: }-3 \mathrm{kN}\end{array}$ & Every $0.5 \mathrm{~mm}$ \\
\hline $2 \mathrm{c}$ & & $\begin{array}{l}\text { Constant amplitude load: } 1.75 \mathrm{kN} \\
\text { Single overload: } 3 \mathrm{kN} \\
\text { Single underload: }-3 \mathrm{kN}\end{array}$ & Every $0.25 \mathrm{~mm}$ \\
\hline $3 a$ & \multirow{3}{*}{ MLMWMMMLMUM } & $\begin{array}{l}\text { Constant amplitude load: } 1.75 \mathrm{kN} \\
5 \text { Block overload: } 3 \mathrm{kN}\end{array}$ & 3.25 and $5.25 \mathrm{~mm}$ \\
\hline $3 b$ & & $\begin{array}{l}\text { Constant amplitude load: } 1.75 \mathrm{kN} \\
5 \text { Block overload: } 3 \mathrm{kN}\end{array}$ & Every $0.5 \mathrm{~mm}$ \\
\hline $3 \mathrm{c}$ & & $\begin{array}{l}\text { Constant amplitude load: } 1.75 \mathrm{kN} \\
5 \text { Block overload: } 3 \mathrm{kN}\end{array}$ & Every $0.25 \mathrm{~mm}$ \\
\hline $4 a$ & \multirow{3}{*}{ MuMMM MWN $^{\text {MWN }}$} & $\begin{array}{l}\text { Constant amplitude load: } 1.75 \mathrm{kN} \\
5 \text { Block overload: } 3 \mathrm{kN} \\
5 \text { Block underload: }-3 \mathrm{kN}\end{array}$ & 3.25 and $5.25 \mathrm{~mm}$ \\
\hline $4 \mathrm{~b}$ & & $\begin{array}{l}\text { Constant amplitude load: } 1.75 \mathrm{kN} \\
5 \text { Block overload: } 3 \mathrm{kN} \\
5 \text { Block underload: }-3 \mathrm{kN}\end{array}$ & Every $0.5 \mathrm{~mm}$ \\
\hline $4 \mathrm{c}$ & & $\begin{array}{l}\text { Constant amplitude load: } 1.75 \mathrm{kN} \\
5 \text { Block overload: } 3 \mathrm{kN} \\
5 \text { Block underload: }-3 \mathrm{kN}\end{array}$ & Every $0.25 \mathrm{~mm}$ \\
\hline
\end{tabular}




\subsection{Closure/Opening measurements}

In order to measure the opening stresses the machine was stopped, at the mean load, when the crack reached the lengths of 3.25 and $5.25 \mathrm{~mm}$ (including notch). It was decided to define the crack opening or closing criterion as the load at which the crack surfaces start to touch or separate at a distance around $25 \mu \mathrm{m}$ behind the crack tip. This varied normally by $\pm 10 \mu \mathrm{m}$, because of the non-uniformity of the crack shape, although some larger variations were found for specific loading conditions.

\subsection{Periodic Loading}

One particular case of variable amplitude load is the periodic application of loads. To examine this case, a constant amplitude base load of $1.75 \mathrm{kN}$ was selected at stress ratio $R=0$, and overloads of $2.5 \mathrm{kN}$ were applied twice. The criterion of releasing each node every 2 cycles was kept. The opening and closure stresses were measured in the second applied cycle (3), as discussed in section 3.

\subsection{Spectrum Loading}

Spectrum loading was simulated employing the numerical model utilising a randomised history load. The loads were selected randomly with a stress range of $R=0$, with the applied load range set to be within $0.15 \leq \mathrm{P} \leq 1.85 \mathrm{kN}$. The release node technique was every 2 cycles, as with all the previous cases.

\section{Numerical Procedure}

A two dimensional plane stress Finite Element model was developed previously by the authors (3) and validated using constant amplitude loading. These models have been extended in this work to include the effects of single overloads and underloads and block overloads and underloads. The loading and dimensions of the models replicated the experimental tests (2). The Finite Element model used the restart facility within ABAQUS and mesh refinement to enable cracks up to $5.25 \mathrm{~mm}$ to be modelled with a minimum element size of $3.91 \mu \mathrm{m}$. The element size was based on how well the models matched the plastic zones predicted analytically (3) but were also based on seeing crack growth jumps of 5-10 $\mu \mathrm{m}$ in SEM images taken from the experimental test specimens (2). The yield strength of the material was set to be 298 $\mathrm{MPa}(2)$ and hardening was applied using isotropic hardening based on the work by Gonzalez-Herrera and Zapatero (40). The material properties used in the hardening rule, based on cyclic hardening, were obtained by the Ramberg Osgood relationship. The hardening coefficient $H=443 \mathrm{MPa}$ and the hardening exponent $n=0.064$ were obtained from Borrego et al. $(41,42)$. The crack was grown in the numerical models by applying two load cycles and releasing the crack tip node just after the maximum load on the second load cycle. Measurements of crack closing and opening loads were carried out on the second load cycle by measuring the displacement of the node behind the crack tip (and contact pressure, using the augmented Lagrange method (43)). Numerical predictions of crack growth for overload cases were obtained by using constants $\mathrm{C}$ and $\mathrm{m}$ in the Elber equation. The Elber constants were obtained by plotting the log of the effective stress intensity, obtained from constant amplitude numerical models (3), against the crack growth data from constant amplitude tests (2). The effective stress intensity (Keff) was calculated using three different methods: 
1) Maximum stress intensity $\left(\mathrm{K}_{\max }\right)$ minus the opening $\left(\mathrm{K}_{\mathrm{op}}\right)$ and closing $\left(\mathrm{K}_{\mathrm{cl}}\right)$ stress intensities divided by two.

2) Same method as 1 to determine initial $K_{\text {eff }}$ 's but then an average is used at the mid point between nodes by taking the $\mathrm{K}_{\mathrm{eff}}$ at the current node and $\mathrm{K}_{\mathrm{eff}}$ at the next node and dividing by two.

3) Maximum stress intensity minus the opening stress intensity.

The stress intensity factors $\left(\mathrm{K}_{\mathrm{I}}\right)$ were calculated using Eq. (1) using geometry factor $\mathrm{F}(\alpha)$, where $\boldsymbol{\sigma}_{\boldsymbol{a}}$ and $\boldsymbol{a}$ are the (applied) nominal bending stress (at the opening or closing load, $\boldsymbol{P}_{\boldsymbol{o p}}$ or $\left.\boldsymbol{P}_{c l}\right)$ and the crack length respectively.

$$
K_{I}=\sigma_{a} * F(\alpha) * \sqrt{\pi a}
$$

For single edge four point bend specimens the geometry factor $F(\alpha)$ is given by Eq. (2), where $\boldsymbol{\alpha}$ is given by Eq. (3) and W is the depth of the specimen (see Fig.1).

$$
\begin{gathered}
F(\alpha)=1.122-1.12 \alpha+3.74 \alpha^{2}+3.783 \alpha^{3}-19.05 \alpha^{4}+22.55 \alpha^{5} \\
\alpha=\frac{a}{W}
\end{gathered}
$$

\section{Results and Discussions}

\subsection{Experimental and numerical opening and closure load values}

A transition mesh was used in the numerical models along the initial $5.25 \mathrm{~mm}$ crack path. This was done to improve crack closure measurements in this region. Subsequent to making this decision it was found that at the transition location between meshes (mesh interface) the opening and closure stresses cannot be obtained with confidence (44). Due to this overload information at crack lengths of $5.25 \mathrm{~mm}$ was ignored and subsequent models were not loaded at this crack length. Experimental overloads, for all cases, were applied at both $3.25 \mathrm{~mm}$ and $5.25 \mathrm{~mm}$.

Some specific differences can be seen in the opening and closure loads when comparing the experimental and numerical results, presented in Table 3. The position of measurement behind the crack tip is seen to have a significant effect. Some large discrepancies were found between some of the experimental and numerical values, see percentage errors in Table 3. This discrepancy may originate because the opening values were obtained one node behind the crack tip on the numerical model, which corresponds to $3.90625 \mu \mathrm{m}$, but experimentally the data was taken between $15 \mu \mathrm{m}$ to $35 \mu \mathrm{m}$ behind the crack tip. The position at which measurements were made experimentally was recorded for some tests in Table 3 to see how this corresponds with numerical results taken further back from the crack tip (value in brackets in opening and closing load columns gives the position behind the crack tip that opening and closing was measured). For these tests numerical results for crack opening and closing loads have been given 6 or 8 nodes behind the crack tip, 8 nodes represents a distance of $31.25 \mu \mathrm{m}$ and 6 nodes represents a distance of $23.44 \mu \mathrm{m}$. The number in brackets in the error column is based on the revised numerical measurements, taken 6 or 8 nodes behind the crack tip. 
Table 3

Opening stress values at crack length $3.25 \mathrm{~mm}$, after applied overload

\begin{tabular}{|c|c|c|c|c|c|c|}
\hline \multicolumn{7}{|c|}{ Opening and closure load values - Experimental vs. ABAQUS } \\
\hline \multirow{3}{*}{$\begin{array}{c}\text { Type } \\
\text { of } \\
\text { load }\end{array}$} & \multicolumn{6}{|c|}{$0.00390625 \mathrm{~mm}$ Mesh size } \\
\hline & \multicolumn{2}{|c|}{ Opening kN (P/2) } & \multirow{2}{*}{$\begin{array}{l}\text { Average } \\
\text { Error \% }\end{array}$} & \multicolumn{2}{|c|}{ Closure $\mathrm{kN}(\mathrm{P} / 2)$} & \multirow{2}{*}{$\begin{array}{l}\text { Average } \\
\text { Error } \%\end{array}$} \\
\hline & ABAQUS & Experimental & & Experimental & ABAQUS & \\
\hline \multirow{2}{*}{$1 a$} & \multirow{2}{*}{$\begin{array}{c}0.189 \\
0.33 \\
\text { (8 nodes) }\end{array}$} & 0.35 & \multirow{2}{*}{$\begin{array}{c}46.0 \\
(5.71)\end{array}$} & 0.225 & \multirow{2}{*}{$\begin{array}{c}0.131 \\
0.26 \\
\text { (8 nodes) }\end{array}$} & \multirow{2}{*}{$\begin{array}{l}44.8 \\
(-9.5)\end{array}$} \\
\hline & & $0.35(0.05)$ & & $0.25(0.05)$ & & \\
\hline \multirow{3}{*}{$1 \mathrm{~b}$} & \multirow{3}{*}{0.283} & 0.26 & \multirow{3}{*}{-3.5} & 0.175 & \multirow{3}{*}{0.218} & \multirow{3}{*}{-13.7} \\
\hline & & 0.31 & & 0.25 & & \\
\hline & & 0.25 & & 0.15 & & \\
\hline \multirow{3}{*}{$1 \mathrm{c}$} & \multirow{3}{*}{0.378} & 0.25 & \multirow{3}{*}{-68.0} & 0.15 & \multirow{3}{*}{0.35} & \multirow{3}{*}{-156.1} \\
\hline & & 0.125 & & 0.06 & & \\
\hline & & 0.3 & & 0.2 & & \\
\hline \multirow{3}{*}{$2 a$} & \multirow{3}{*}{$\begin{array}{c}0.189 \\
0.33 \\
\text { (8 nodes) }\end{array}$} & 0.35 & \multirow{3}{*}{$\begin{array}{c}41.8 \\
(-1.5)\end{array}$} & 0.2 & \multirow{3}{*}{$\begin{array}{c}0.131 \\
0.218 \\
\text { (6 nodes) }\end{array}$} & \\
\hline & & $0.325(0.03)$ & & $0.225(0.03)$ & & $\begin{array}{c}3 / .1 \\
(-4.64)\end{array}$ \\
\hline & & 0.3 & & 0.2 & & \\
\hline & 0.212 & 0.325 & & 0.225 & & \\
\hline $2 b$ & 0.35 & $0.35(0.035)$ & 31.2 & 0.25 & 0.175 & 19.2 \\
\hline & & 0.25 & & 0.175 & & \\
\hline & & 0.19 & & 0.225 & & \\
\hline $2 c$ & 0.378 & 0.25 & -48.2 & 0.18 & 0.306 & -49.2 \\
\hline & & 0.325 & & 0.21 & & \\
\hline & & 0.15 & & 0.075 & & \\
\hline $3 a$ & 0.189 & 0.18 & 6.3 & 0.08 & 0.131 & -19.1 \\
\hline & & 0.275 & & 0.175 & & \\
\hline & & 0.255 & & 0.175 & & \\
\hline $3 b$ & 0.283 & 0.3 & -19.2 & 0.19 & 0.218 & -37.6 \\
\hline & & 0.1575 & & 0.11 & & \\
\hline & & 0.2875 & & 0.17 & & \\
\hline $3 c$ & 0.378 & 0.3 & -27.1 & 0.275 & 0.35 & -68.7 \\
\hline & & 0.305 & & 0.1775 & & \\
\hline & 0.189 & 0.205 & & 0.14 & 0.131 & \\
\hline $4 a$ & 0.283 & 0.3 & $\begin{array}{c}24.4 \\
(-132)\end{array}$ & 0.265 & 0.175 & $\begin{array}{c}32.8 \\
(103)\end{array}$ \\
\hline & (6 nodes) & $0.245(0.025)$ & & $0.18(0.025)$ & (6 nodes) & \\
\hline & & 0.1925 & & 0.01525 & & \\
\hline $4 b$ & 0.283 & 0.1375 & -79.6 & 0.08 & 0.218 & -214.8 \\
\hline & & 0.1425 & & 0.1125 & & \\
\hline & & 0.245 & & 0.1975 & & \\
\hline $4 c$ & 0.378 & 0.26 & -74.4 & 0.1325 & 0.306 & -118.5 \\
\hline & & 0.145 & & 0.09 & & \\
\hline
\end{tabular}

The opening and closing loads measured in the FE models are significantly affected by the cyclic plasticity rule used, the application of block overloads on a single node, the distance between nodes and the node position at which the opening and closing loads are measured, see sections $4.5,4.8$ and 4.9. 
Within this section the opening and closing loads are presented for the twelve overload cases and in addition for the cases of periodic and spectrum loading. Some initial observations are presented but more detailed analysis is presented in later sections.

\subsubsection{Single applications of different patterns of overload/underload}

Single overload patterns were applied at a crack length of $3.25 \mathrm{~mm}$ within a constant amplitude loading regime. The results are shown in Fig. 2, where four different load cases are presented: 1a, 2a, 3a and 4a. From the figure it can be observed that the highest values of opening and closure are for the cases of single (1a) and block overload (3a). The case $2 \mathrm{a}$ of single overload/underload showed the lowest opening value, followed by case $4 \mathrm{a}$ where five overload and five underload cycles were applied consecutively. The closure results are similar to the opening case for the four patterns as can be seen in Fig. 2b. Steady state values of opening and closure stresses were reached again after the overload patterns were applied. The distance ahead of the overload point at which this occurred was around $0.65 \mathrm{~mm}$ for the case of opening, and $0.625 \mathrm{~mm}$ for the case of closure. 

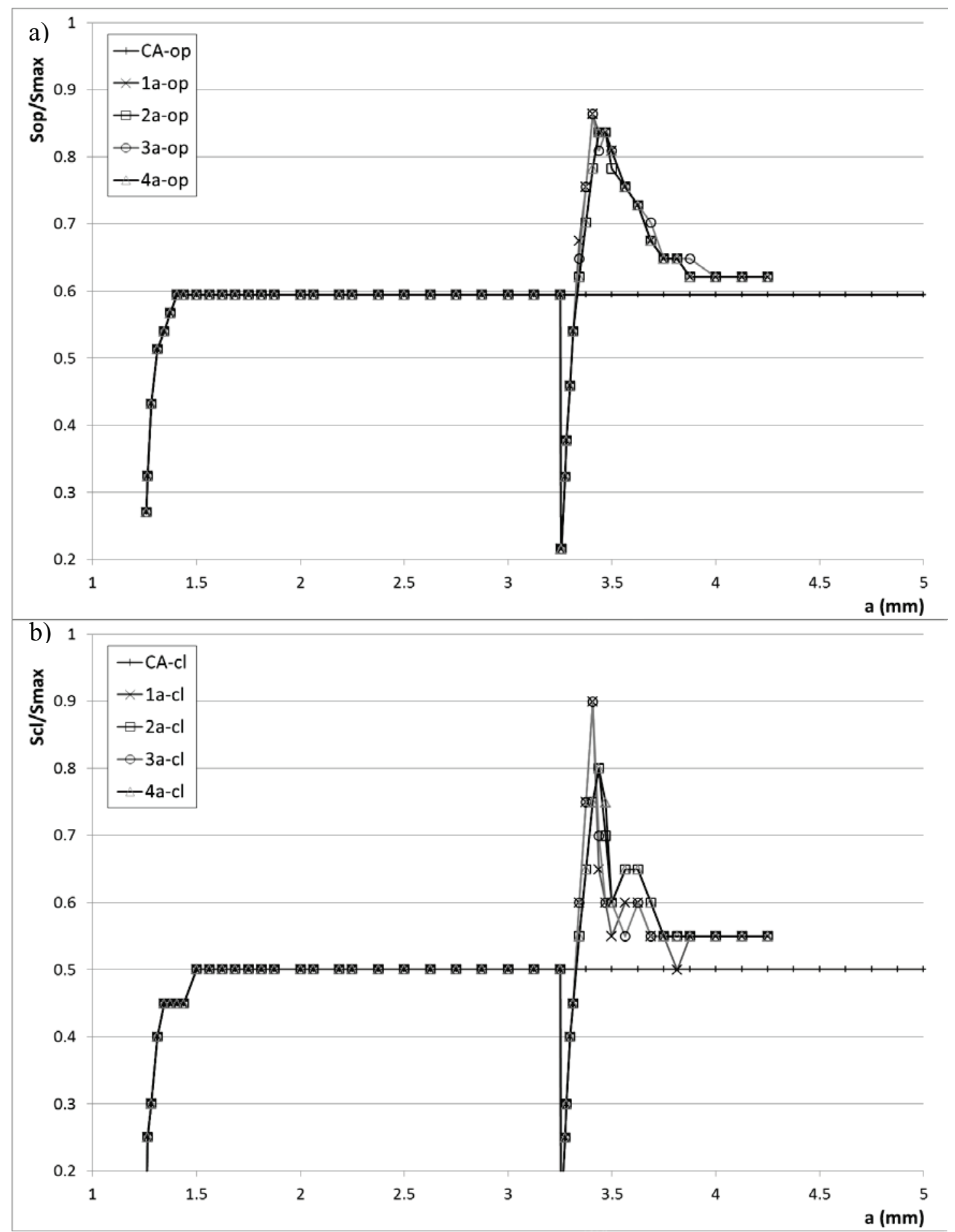

Fig 2. Opening (a) and closure (b) stresses for overload applied at $3.25 \mathrm{~mm}$ along the crack length for all the cases $1,2,3$ and 4 . $R=0$.

\subsubsection{Overloads applied every 0.5 millimetres and every 0.25 millimetres}

In the case of overload patterns applied every $0.5 \mathrm{~mm}$ and $0.25 \mathrm{~mm}$, cases $1 \mathrm{~b}, 2 \mathrm{~b}, 3 \mathrm{~b}$ and $4 \mathrm{~b}$, steady state is not obtained. This can be seen in Fig. 3 where the cases for overloads applied every $0.25 \mathrm{~mm}$ are presented. 

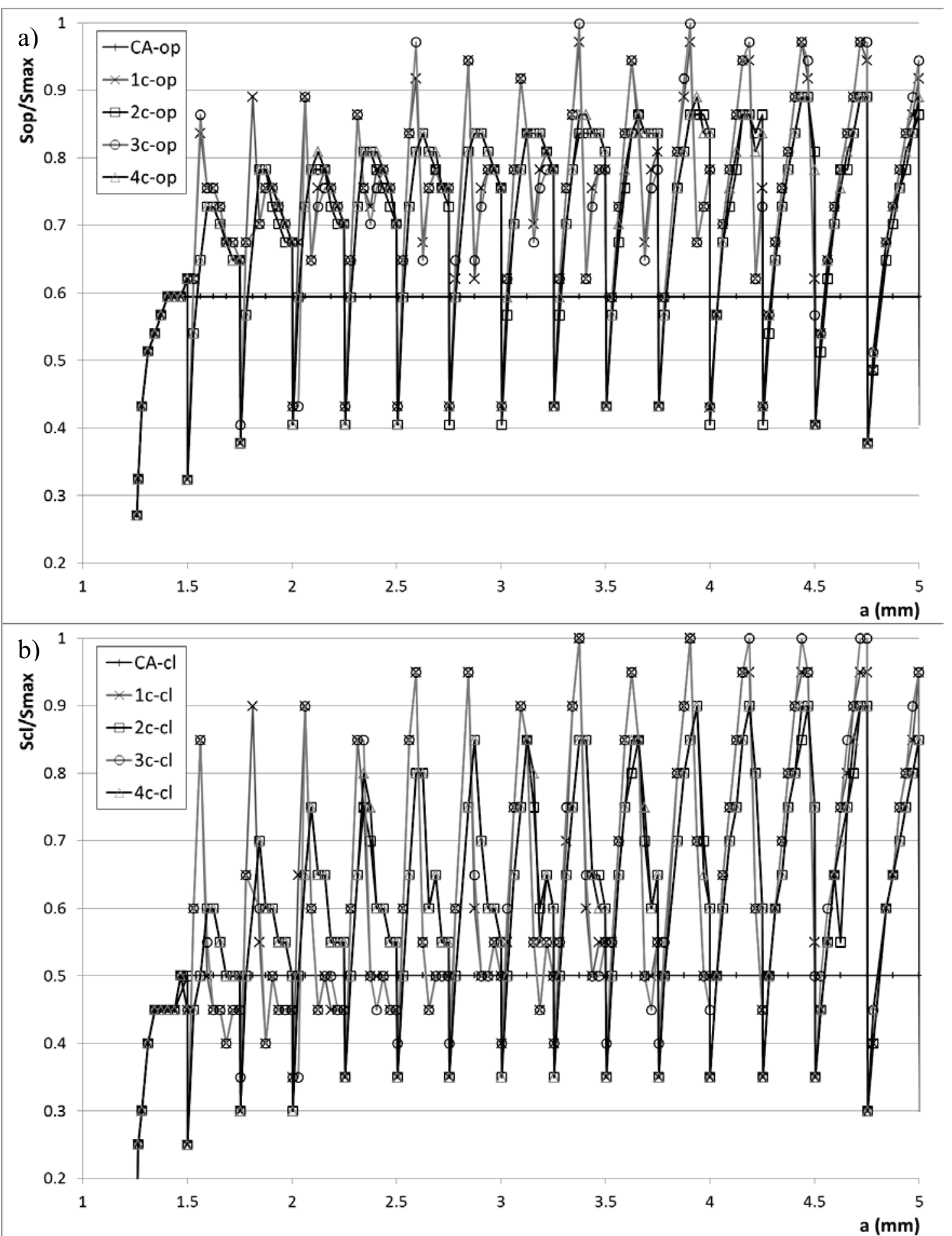

Fig 3. Opening (a) and closure (b) stresses for single overload cases applied every $0.25 \mathrm{~mm}$ along the crack length for all the cases $1,2,3$ and 4. $R=0$.

The lowest crack growth rates were obtained in this pattern of overloads, see section 4.3, which would be due to the higher opening and closure loads (see Fig. 3 in comparison to Fig. 2).

\subsubsection{Periodic loading}

The results of the simulation showed a periodic pattern on the opening and closure stresses as is illustrated in Fig. 4. The increase on the opening stresses with respect to 
the constant amplitude base curve was around 30\% whereas the stress level was increased $42.8 \%$. The closure stresses showed an increase around $28.7 \%$. The model showed high sensitivity; and it was observed that there were different stress opening amplitudes between each set of 2 cycles applied. Also a steady state was observed at $\mathrm{a} / \mathrm{W}=0.0157$ and a decreasing tendency was present in both opening and closure stresses after $\mathrm{a} / \mathrm{W} \approx 0.11$.
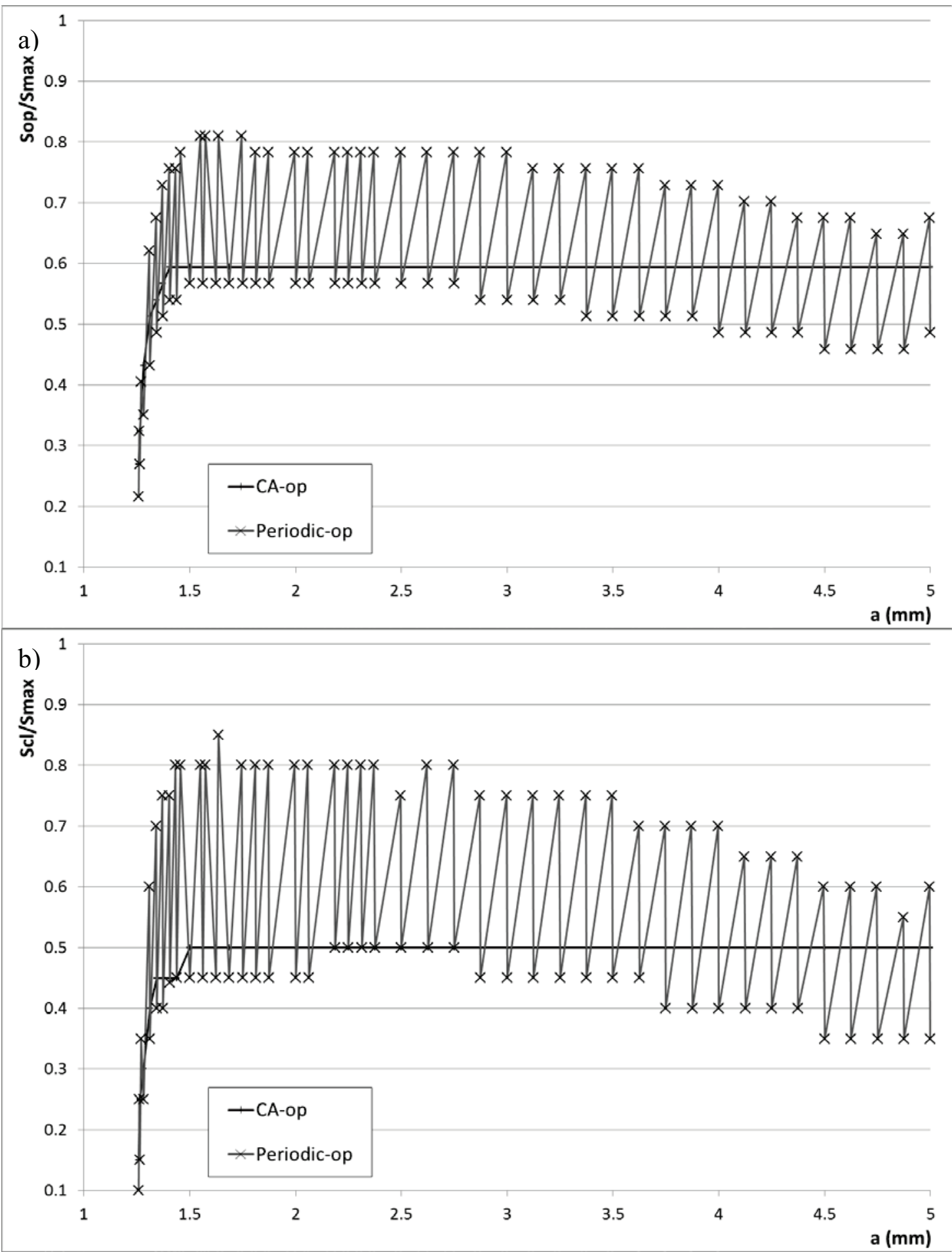

Fig 4. Opening a), and closure b) stress response during periodic overload. $R=0$, mesh size $0.00390625 \mathrm{~mm}$. 


\subsubsection{Spectrum loading}

Fig. 5 shows the load amplitude of the applied spectrum load. As with the case of periodic load, the model had high sensitivity to changes in the opening and closure stresses. Different values were obtained between two consecutive loads of the same amplitude. The opening and closure stresses are shown in Fig. 6. In this figure it is possible to observe that no opening occurred at some points as the applied load was smaller than the required opening load. With this behaviour it is expected that lower crack growth $d a / d N$ will occur, using the stress ratio $\mathrm{R}=0$.

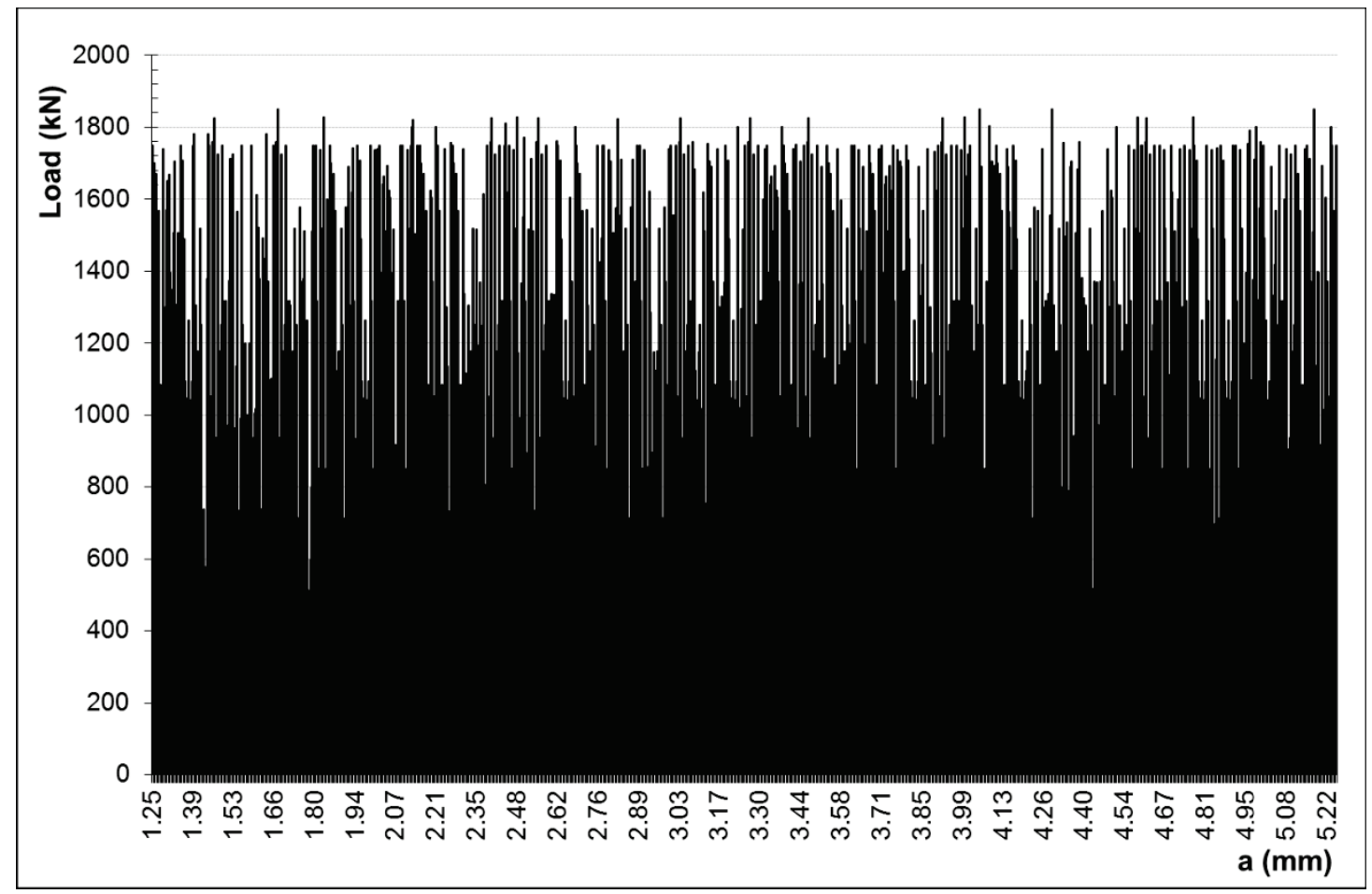

Fig 5. Spectrum load case along $5.25 \mathrm{~mm}$ crack length. $\mathrm{R}=0, \Delta \mathrm{a}=000390625 \mathrm{~mm}$. 

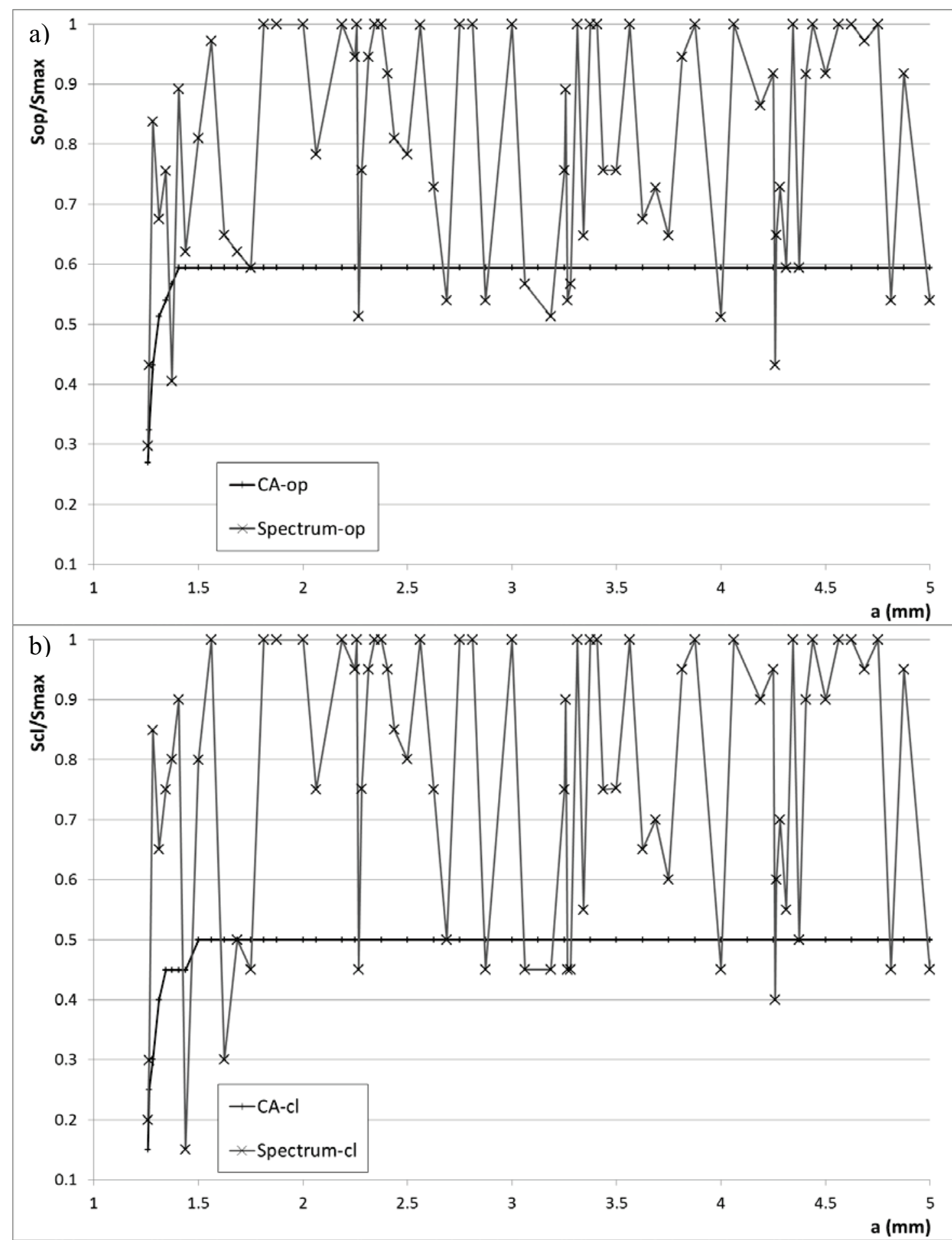

Fig 6. Opening a) and closure b) stress response during spectrum load. $R=0$, mesh size $0.00390625 \mathrm{~mm}$.

\subsection{Crack opening stress after overload application}

Table 4 shows the maximum normalised opening stress values for the twelve load cases after the application of an overload and the crack length at which they occur. The numbers correspond to the peaks shown in Figs. 2 and 3. Normalised closure stresses have not been included in the table as they follow similar trends. 
Table 4

Maximum normalised opening stresses $\left(\mathrm{S}_{\mathrm{op}} / \mathrm{S}_{\max }\right)$, and crack length position, after application of an overload.

\begin{tabular}{|c|c|c|c|c|c|c|c|c|c|c|c|c|c|c|c|c|}
\hline Case & Overload Position $(\mathrm{mm}) \mid$ & 1.5 & 1.75 & 2 & 2.25 & 2.5 & 2.75 & 3 & 3.25 & 3.5 & 3.75 & 4 & 4.25 & 4.5 & 4.75 & 5 \\
\hline \multirow{2}{*}{$1 a$} & Crack length (mm) & & & & & & & & 3.406 & & & & & & & \\
\hline & Sop/Smax & & & & & & & & 0.864 & & & & & & & \\
\hline \multirow{2}{*}{$1 b$} & Crack length $(\mathrm{mm})$ & & 1.813 & & 2.438 & & 2.875 & & 3.375 & & 3.938 & & 4.500 & & 5.125 & \\
\hline & Sop/Smax & & 0.809 & & 0.783 & & 0.809 & & 0.864 & & 0.944 & & 0.944 & & 0.944 & \\
\hline \multirow{2}{*}{$1 \mathrm{c}$} & Crack length (mm) & 1.563 & 1.813 & 2.063 & 2.313 & 2.594 & 2.844 & 3.094 & 3.375 & 3.625 & 3.906 & 4.156 & 4.438 & 4.719 & 5.000 & 5.250 \\
\hline & Sop/Smax & 0.837 & 0.890 & 0.890 & 0.864 & 0.918 & 0.944 & 0.918 & 0.971 & 0.944 & 0.971 & 0.944 & 0.971 & 0.971 & 0.918 & 0.999 \\
\hline \multirow{2}{*}{$2 a$} & Crack length $(\mathrm{mm})$ & & & & & & & & 3.438 & & & & & & & \\
\hline & Sop/Smax & & & & & & & & 0.837 & & & & & & & \\
\hline \multirow{2}{*}{$2 b$} & Crack length $(\mathrm{mm})$ & & 1.875 & & 2.375 & & 2.875 & & 3.438 & & 4.000 & & 4.563 & & 5.125 & \\
\hline & Sop/Smax & & 0.783 & & 0.809 & & 0.809 & & 0.837 & & 0.864 & & 0.864 & & 0.890 & \\
\hline \multirow{2}{*}{$2 c$} & Crack length (mm) & 1.594 & 1.844 & 2.094 & 2.344 & 2.625 & 2.875 & 3.125 & 3.375 & 3.656 & 3.906 & 4.156 & 4.438 & 4.719 & 5.000 & 5.250 \\
\hline & Sop/Smax & 0.728 & 0.783 & 0.783 & 0.809 & 0.837 & 0.837 & 0.837 & 0.837 & 0.864 & 0.864 & 0.864 & 0.890 & 0.890 & 0.864 & 0.890 \\
\hline \multirow{2}{*}{ 3a } & Crack length (mm) & & & & & & & & 3.406 & & & & & & & \\
\hline & Sop/Smax & & & & & & & & 0.864 & & & & & & & \\
\hline \multirow{2}{*}{$3 b$} & Crack length $(\mathrm{mm})$ & & 1.813 & & 2.406 & & 2.875 & & 3.375 & & 3.938 & & 4.500 & & 5.125 & \\
\hline & Sop/Smax & & 0.809 & & 0.783 & & 0.837 & & 0.864 & & 0.944 & & 0.944 & & 0.971 & \\
\hline \multirow{2}{*}{$3 c$} & Crack length (mm) & 1.563 & 1.875 & 2.156 & 2.313 & 2.594 & 2.844 & 3.094 & 3.375 & 3.625 & 3.906 & 4.188 & 4.438 & 4.719 & 5.000 & 5.250 \\
\hline & Sop/Smax & 0.864 & 0.755 & 0.755 & 0.864 & 0.971 & 0.944 & 0.918 & 0.999 & 0.944 & 0.999 & 0.971 & 0.971 & 0.971 & 0.944 & 0.999 \\
\hline \multirow{2}{*}{$4 a$} & Crack length (mm) & & & & & & & & 3.438 & & & & & & & \\
\hline & Sop/Smax & & & & & & & & 0.837 & & & & & & & \\
\hline \multirow{2}{*}{$4 \mathrm{~b}$} & Crack length (mm) & & 1.875 & & 2.375 & & 2.875 & & 3.438 & & 4.000 & & 4.563 & & 5.125 & \\
\hline & Sop/Smax & & 0.783 & & 0.809 & & 0.809 & & 0.837 & & 0.864 & & 0.864 & & 0.890 & \\
\hline \multirow{2}{*}{$4 c$} & Crack length (mm) & 1.594 & 1.844 & 2.125 & 2.344 & 2.625 & 2.875 & 3.125 & 3.375 & 3.656 & 3.938 & 4.156 & 4.438 & 4.719 & 5.000 & 5.250 \\
\hline & Sop/Smax & 0.728 & 0.783 & 0.809 & 0.809 & 0.837 & 0.837 & 0.837 & 0.864 & 0.864 & 0.890 & 0.864 & 0.890 & 0.890 & 0.890 & 0.890 \\
\hline
\end{tabular}

\subsection{Comparison of experimental and numerical crack growth rates}

In order to predict the crack growth for the different overload cases the Elber constants $\mathrm{m}$ and $\mathrm{C}$ were obtained by fitting crack growth data from five constant amplitude tests (2) with $\mathrm{K}_{\text {eff }}$ data obtained from a constant amplitude numerical model (3). The data was fitted over the crack length range of $\mathrm{a}=2.25 \mathrm{~mm}$ to $5.25 \mathrm{~mm}$. $2.25 \mathrm{~mm}$ represents the point at which the crack has grown one millimetre (experimentally there was a lot of variation in the first $1 \mathrm{~mm}$ of growth) and $5.25 \mathrm{~mm}$ was the total length of crack modelled numerically.

Fig. 7, shows the crack growth rate obtained experimentally for the 12 different load cases. Generally there is an increase in crack growth rate with crack length and a reduction in crack growth rate with increasing load frequency. 


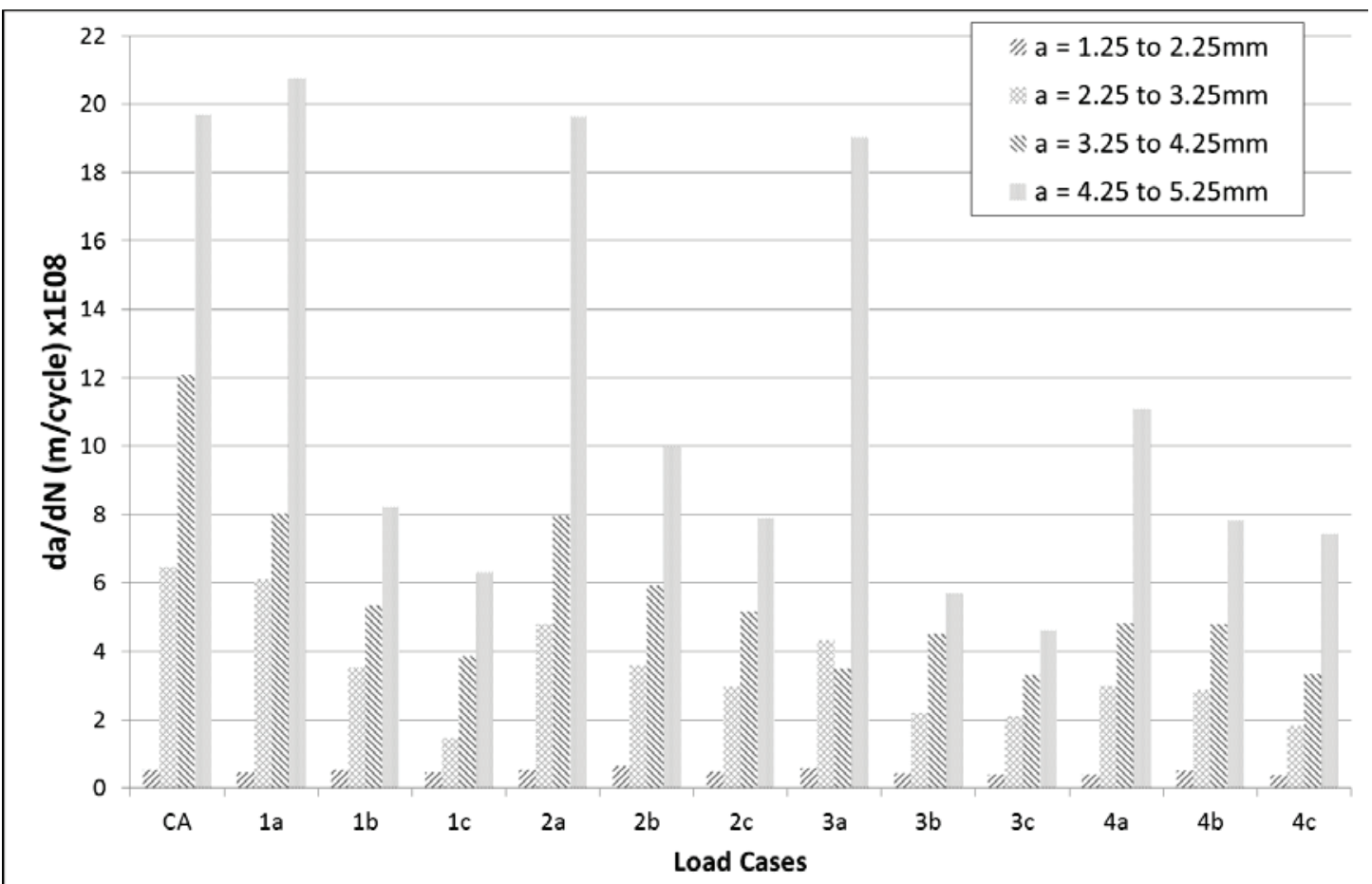

Fig 7. Experimental average values for $d a / d N$ behaviour for $\mathrm{CA}$ and VA loading $\left(\mathrm{R}=0, \mathrm{P}_{\mathrm{MAX}}=1.75 \mathrm{kN}, \mathrm{P}_{\mathrm{O}}= \pm 3 \mathrm{kN}\right)$.

Fig. 8, shows the crack growth rate obtained numerically for the 12 different load cases. There is a drop in crack growth rate for all cases with increasing load frequency. Load cases 1 and 3 and load cases 2 and 4 have very close results. For cases $1 \mathrm{a}, 2 \mathrm{a}, 3 \mathrm{a}$ and $4 \mathrm{a}$ the average growth rate between 4.25 to $5.25 \mathrm{~mm}$ is the same. This is due to the models reaching steady state opening and closing load values, after the application of the single block overload/underload at $3.25 \mathrm{~mm}$. 


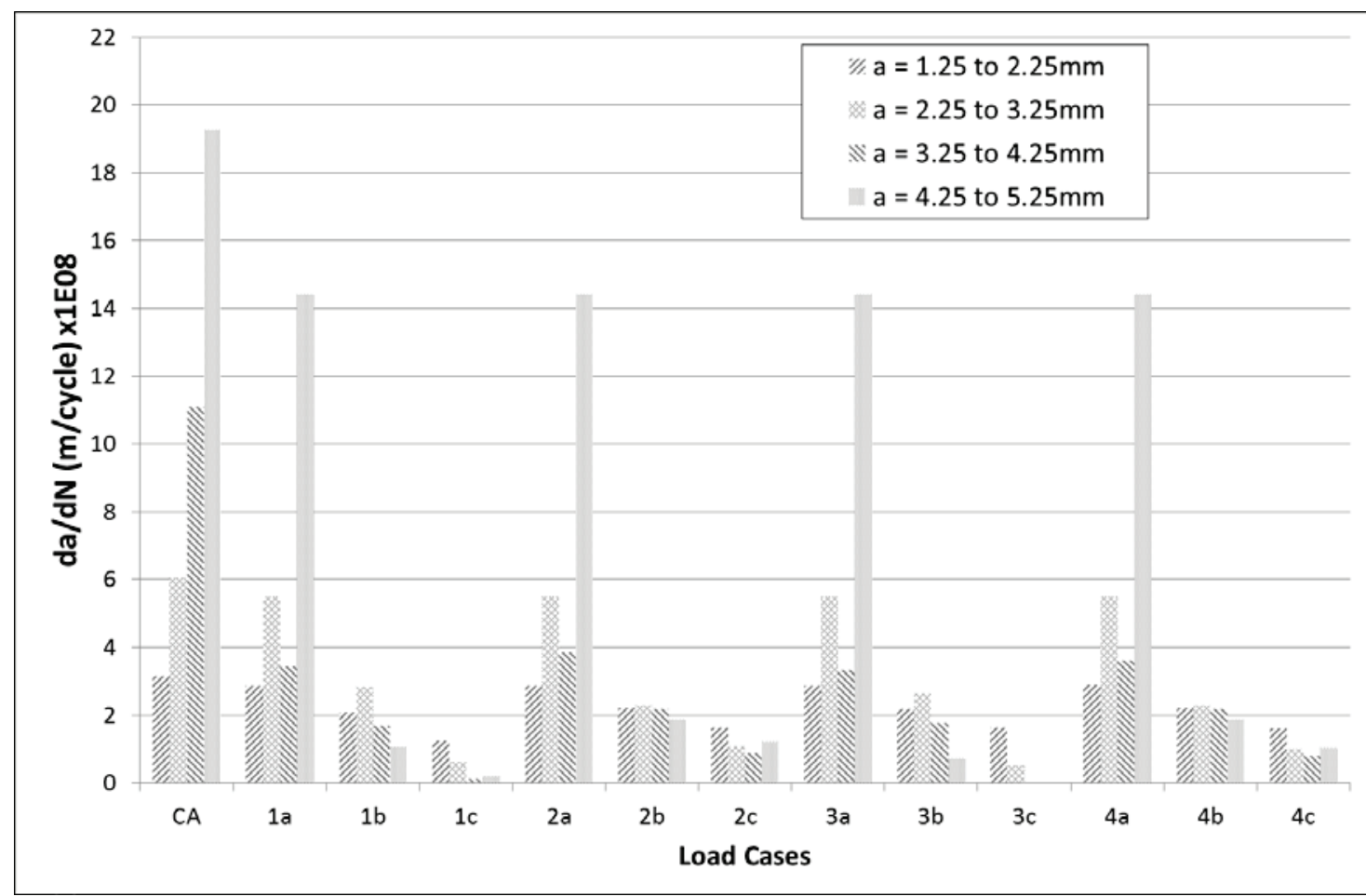

Fig 8. Numerical average values for $\mathrm{da} / \mathrm{dN}$ behaviour for CA and VA loading (Keff=Kmax-Kop, $\left.\mathrm{R}=0, \mathrm{P}_{\mathrm{MAX}}=1.75 \mathrm{kN}, \mathrm{P}_{\mathrm{O}}= \pm 3 \mathrm{kN}\right)$.

Fig. 9 shows a comparison of the numerical and experimental average crack rate growth over the range crack length range $\mathrm{a}=2.25$ to $5.25 \mathrm{~mm}$ for the different cases using different methods of calculating the effective stress intensity factor (see section 3 ). It is clear that as the frequency of load application increases the numerical models start to under predict the crack growth rate. The method where the average value of $\mathrm{K}_{\text {eff }}$ across two points is used at the midpoint between nodes gives closer results to the experimental data. 


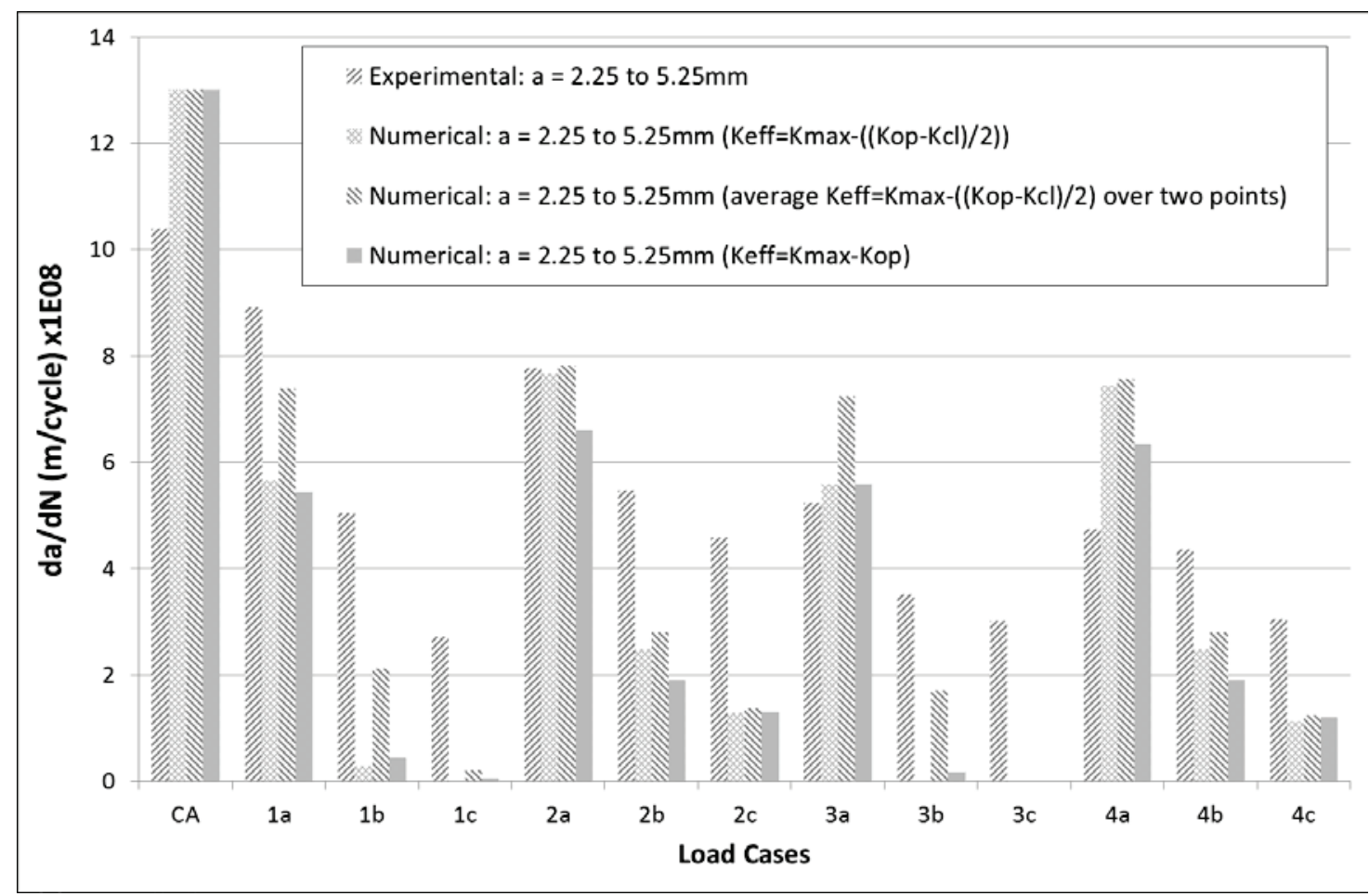

Fig 9. Experimental and numerical average values for $\mathrm{da} / \mathrm{dN}$ behaviour for $\mathrm{CA}$ and VA loading $\left(\mathrm{R}=0, \mathrm{P}_{\mathrm{MAX}}=1.75 \mathrm{kN}, \mathrm{P}_{\mathrm{O}}= \pm 3 \mathrm{kN}\right)$.

It is expected that overloads would reduce the crack growth rate. This is seen both experimentally and numerically. The numerical results though over predict the crack retardation effect. This is seen by the sharper drop in crack growth rate after the single application overload/underload blocks in cases 1a, 2a, 3a and 4a. Also the crack growth rate experimentally continues to increase with crack length for all cases but for the numerical models with high frequency load application the growth rate starts to decrease with crack length. If the crack closure model is correct then this would indicate that the numerical models are generating more plasticity, after overloads, then is real or the model is sensitive to discretisation. Although a mesh convergence study was carried by the authors (3), which was evaluated with respect to the McClung criterion (20), it is likely that the mesh size will still have an effect on the results as the opening and closure values change rapidly after the overload is applied. This would not be captured unless a very fine mesh is used. This is one reason that the use of average stress intensity factors, that smooths out peaks, is producing slightly better results. This though is unlikely to account for the large differences between numerical and experimental results at high load frequency which is likely to be due to the material model generating excess plasticity. It has been shown that $\mathrm{Al}-\mathrm{Mg}-\mathrm{Si}$ Aluminium alloys, such as the 6082 used in this work, are subject to Bauschinger's effect (45) and that at large strain values it is known that the material will start to become anisotropic. These effects are not accommodated by an isotropic hardening rule utilising a von Mises failure criteria. In section 4.8 and 4.9 the effect on crack growth of the chosen material model is discussed and a modification to the material model is introduced in section 4.9 to try to account for some of these issues. In section 4.4 the distance over which the overload has an effect is examined.

\subsection{Crack distance over which overload has effect (interaction period)}


In experimental tests, the initial acceleration produced when an overload is applied is not always captured due to the data recording frequency not being frequent enough. Noroozi (46) does show acceleration experimentally but his analytical model does not capture this acceleration. The same situation was found in the Wheeler model (47), where only a retardation factor $C_{p}$ is calculated immediately after the overload. This was later corrected in a modified Wheeler model developed by Yuan and Taheri (48), who added a delay retardation parameter $\Phi_{D}$. There are other investigations that do not show acceleration effects after single overloads (49, 50). Shijve (51) argues that acceleration is only occasionally observed and this may indicate that acceleration depends on factors such as material conditions, loading amplitude, temperature, etc. In the experimental work carried out by the authors (2) delayed retardation was observed but was not recorded because the $d a / d N$ measurement frequency used was too large (every $0.25 \mathrm{~mm}$ ).

Numerically in this work the same behaviour is seen as shown in the work by Noroozi (46). In addition the interaction effect period was satisfactory captured in terms of crack length by only considering crack closure. In Fig. 10, case a is presented, where a pattern of overloads were applied experimentally at 3.25 and $5.25 \mathrm{~mm}$ crack lengths. 

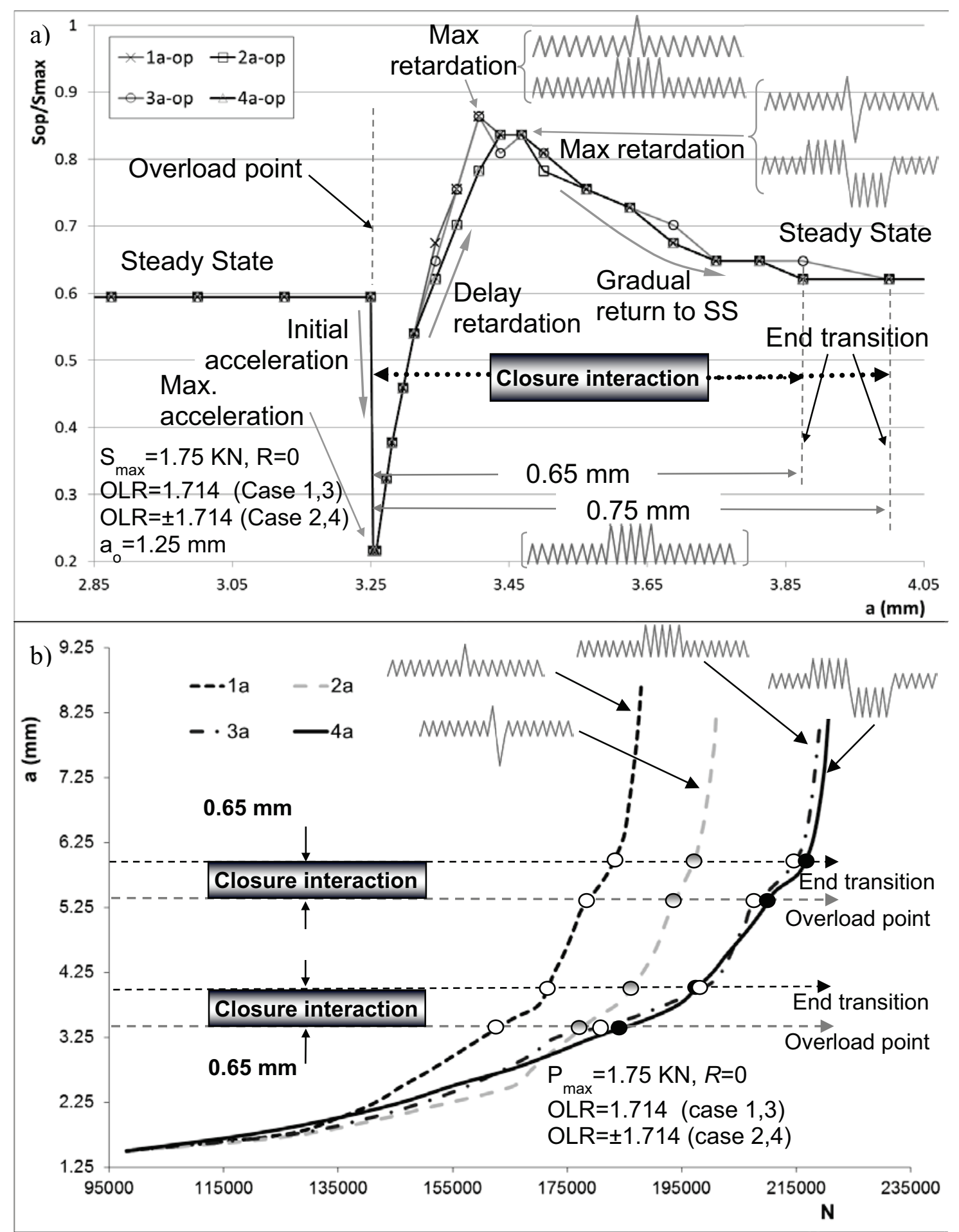

Fig 10. Transition periods attributed to crack closure a) numerical results,

b) experimental results.

The fact that the interaction effect period, in terms of crack length, is similar for both experimental and numerical analysis, suggest that this event can be represented through the crack closure mechanism. Furthermore the opening and closing stresses for the case of block overload/underload patterns (cases $2 \mathrm{a}$ and $4 \mathrm{a}$ ) have lower values which indicates that the flattening of the crack flanks, due to the application of underloads, is being taken into account, see Figs. 2 and 3 and Table 3. Fig. 11, 
illustrates the comparison between experimental findings and numerical calculations for the case $3 \mathrm{a}$ (single application of block loading).
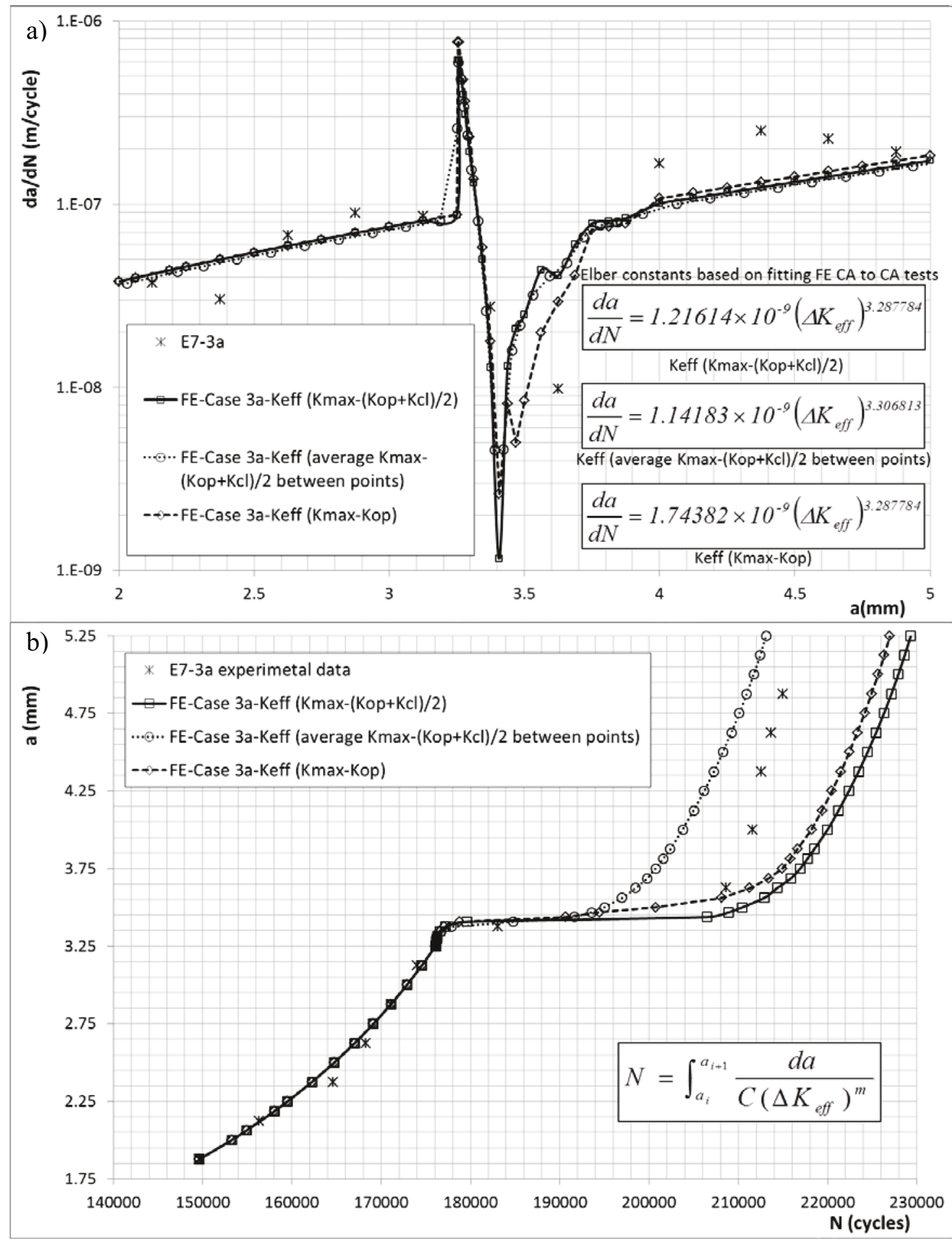

Fig 11. Crack growth rate for case 3a. Comparison between experimental results and FE simulation.

From Fig. 11, the importance of the $d a / d N$ sample frequency during testing can be seen. To compare the curve obtained numerically in Fig. 11a with experimental data would require more frequent measurements, based preferably on cycle steps rather than distance steps. Obtaining accurate measurements of crack growth at short cycle 
steps is though difficult and time consuming. The crack growth data used in this work (2) was taken every $0.25 \mathrm{~mm}$, using specially placed marks on the specimen, which means fully capturing the curve experimentally is impossible. The method using the effective stress intensity based on maximum stress minus opening stress gives the best fit to the data in terms of matching the crack retardation effect, see Fig. 11b.

\subsection{Effect of applying block load at single or consecutive nodes}

It was found that when block overloads (OL's) are applied at consecutive nodes, better values of $S_{o p}$ are obtained than when the complete block is applied at the same node. This might happen because experimentally the crack advances during the period over which the block of overloads is applied. Fig. 12, shows a comparison of the plasticity strain magnitude (PEMAG) when a block of five overloads is applied at the same node, and when they are applied at consecutive nodes. The plasticity originated by the OL's at the same node is larger in the near zone around the crack tip; however the $r_{p}$ distance is shorter than if the OL's were applied at consecutive nodes, and the plasticity amplitude decreases at a shorter distance after the OL's are applied. When the OL are applied at consecutive nodes there is a better distribution of the plasticity, and bigger amplitudes are generated along the crack length (see Fig. 12), which produces better correlation with the estimations of $d a / d N$ when $\Delta K_{\text {eff }}$ is calculated and introduced into the modified Paris equation $(12,39)$. Also the plastic hump left behind the crack tip is bigger when the OL's are applied at one node, which generates incorrect estimations of the delayed retardation. This is due to the larger near crack tip plasticity generated when applying the overloads at a single node which cause the crack to open and close later in the load cycle as the crack grows through the plasticity previously generated. Hence crack advance must be considered carefully when block overloads are applied numerically. 

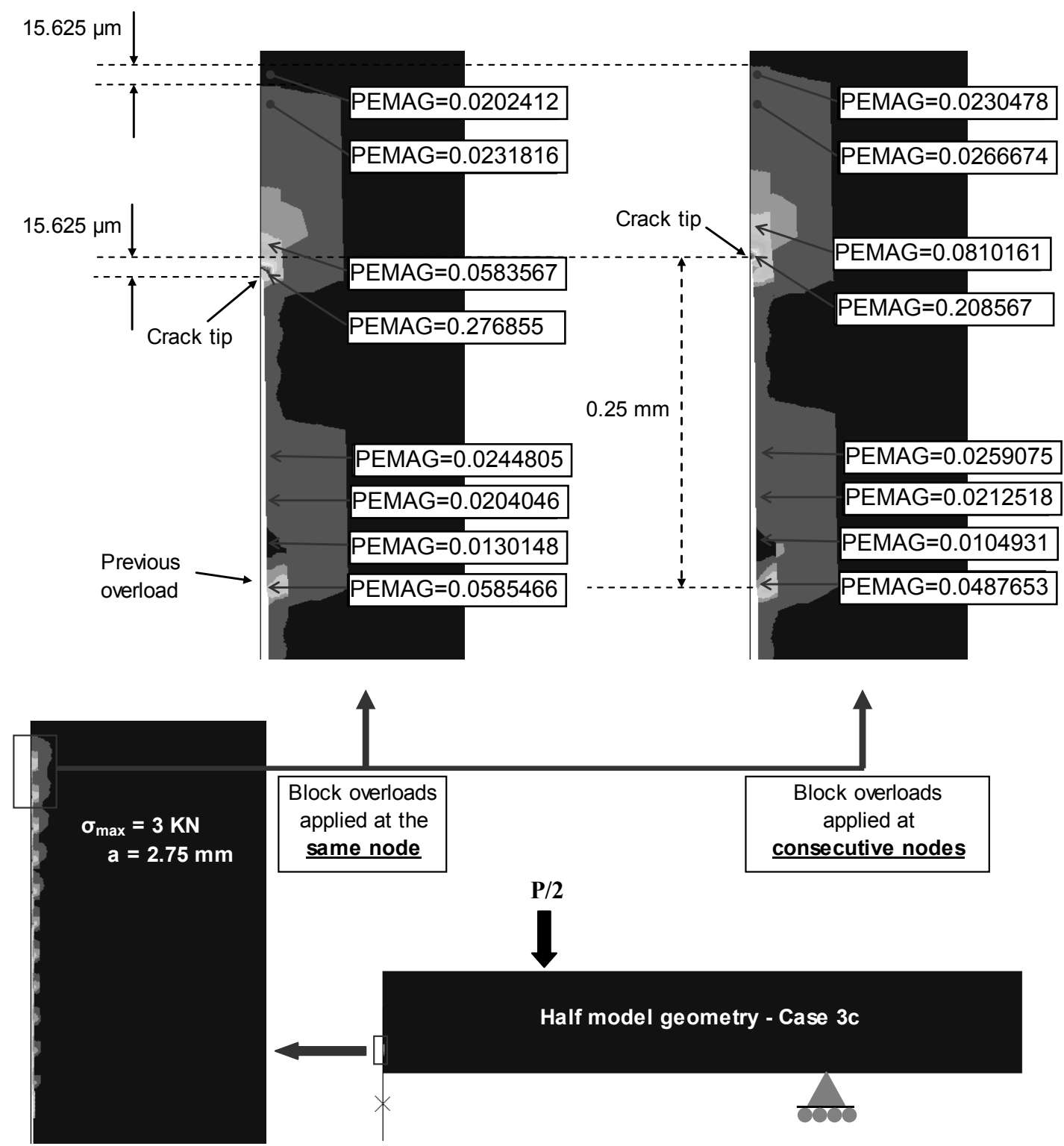

Fig 12. Plasticity recorded at the same node employing two different criteria to apply the block overloads.

\subsection{Effect of applying underloads}

The combination of overload and underload patterns is discussed by Skorupa $(8,9)$. Skorupa analysed several works $(43,52-58)$ that showed that an underload applied after an overload can generate reverse plasticity ahead of the crack tip which partially nullifies the beneficial retardation effect of the overload.

In this work higher effective peak stresses were obtained for cases 1 and 3 over cases 2 and 4 (Figs. 2, 4 and Table 4) but after these peak stresses there is a sharper drop in stress for cases 1 and 3 than for cases 2 and 4 . The overall effect of this seems to be marginal except when the loads are applied every $0.25 \mathrm{~mm}$. When overloads are applied every $0.25 \mathrm{~mm}$ a significant decrease in numerically predicted crack growth rate is found for cases 1 and 3 compared with cases 2 and 4, in line with Skorupa's 
analysis. This was not seen experimentally but that could be due to scatter within the experimental results. The effect of the overload distance is discussed in section 4.7.

\subsection{Effect of overload distance}

In sections 4.4 it was mentioned that after the application of a single pattern of overload, the distance to recover the steady state is around $0.65 \mathrm{~mm}$. This happens in load type cases 1a, 2a, 3a, and 4a. On the other hand, for all other cases (b and c) the patterns of overload were applied at distances shorter than the steady state distance. Numerically when overloads were applied every 0.25 the overload effect was more pronounced than when they are applied every $0.5 \mathrm{~mm}$. Experimentally as the frequency of overloads was increased to $0.5 \mathrm{~mm}$ there was a drop in crack growth rate but when the frequency is further increased to $0.25 \mathrm{~mm}$ the crack growth rate does not drop for cases 3 and 4 . Some possible reasons for the discrepancy between numerical and experimental results are discussed in sections 4.9 and 4.10 .

\subsection{Evaluation of crack opening position}

Crack opening and closure were defined as the points at which the displacement of the first node behind the crack tip changed to positive for the loading cycle and negative for the unloading one, respectively. Remote closure might though occur behind the crack tip due to previously generated plasticity.

To investigate the opening and closing displacements the crack flanks were examined for all the overload/underload cases and for the spectrum load case. Displacement node vectors for case 4 ( $a, b$ and $c)$ plus the spectrum case have been presented in Figs. 13 to 16, where ul represents the distance perpendicular to the crack face.

For case 4a (block overload/underload applied at $3.25 \mathrm{~mm}$ crack length) it can be seen that at the overload point there is a plastic hump that produces a partially open zone of the crack between the crack tip and a remote closure point created by the overload. This situation did not affect the measurement of closure at one node behind the crack tip as the crack tip was still closed when the contact at the previous overload ceases (Fig. 13c). The same effect was observed for the cases 1a, 2a, and 3a. 


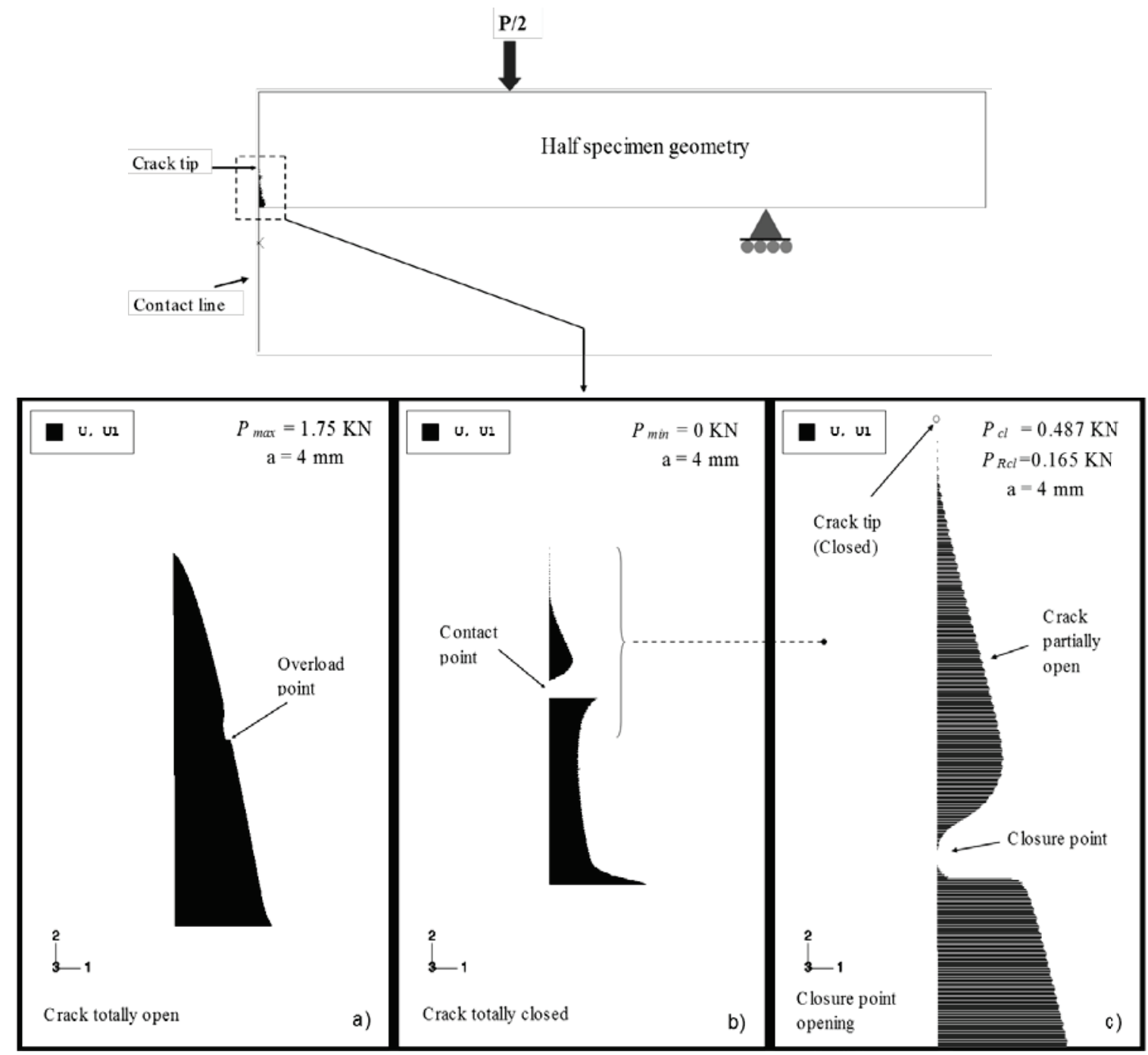

Fig 13. Contact profile for case $4 \mathrm{a}$.

For case $4 \mathrm{~b}$ (block overload/underloads applied every $0.5 \mathrm{~mm}$ ) there are small plastic humps along the length of the crack, see Fig. 14. As the crack was grown it was observed after a block overload/underload was applied the tip remained open during the load cycle at the next node. Similar to case $4 b$, this effect was found in cases $1 b$, $2 \mathrm{~b}$, and $3 \mathrm{~b}$. This only occurs at the overload point and the subsequent node. After this crack closure occurs one node behind the crack tip. 


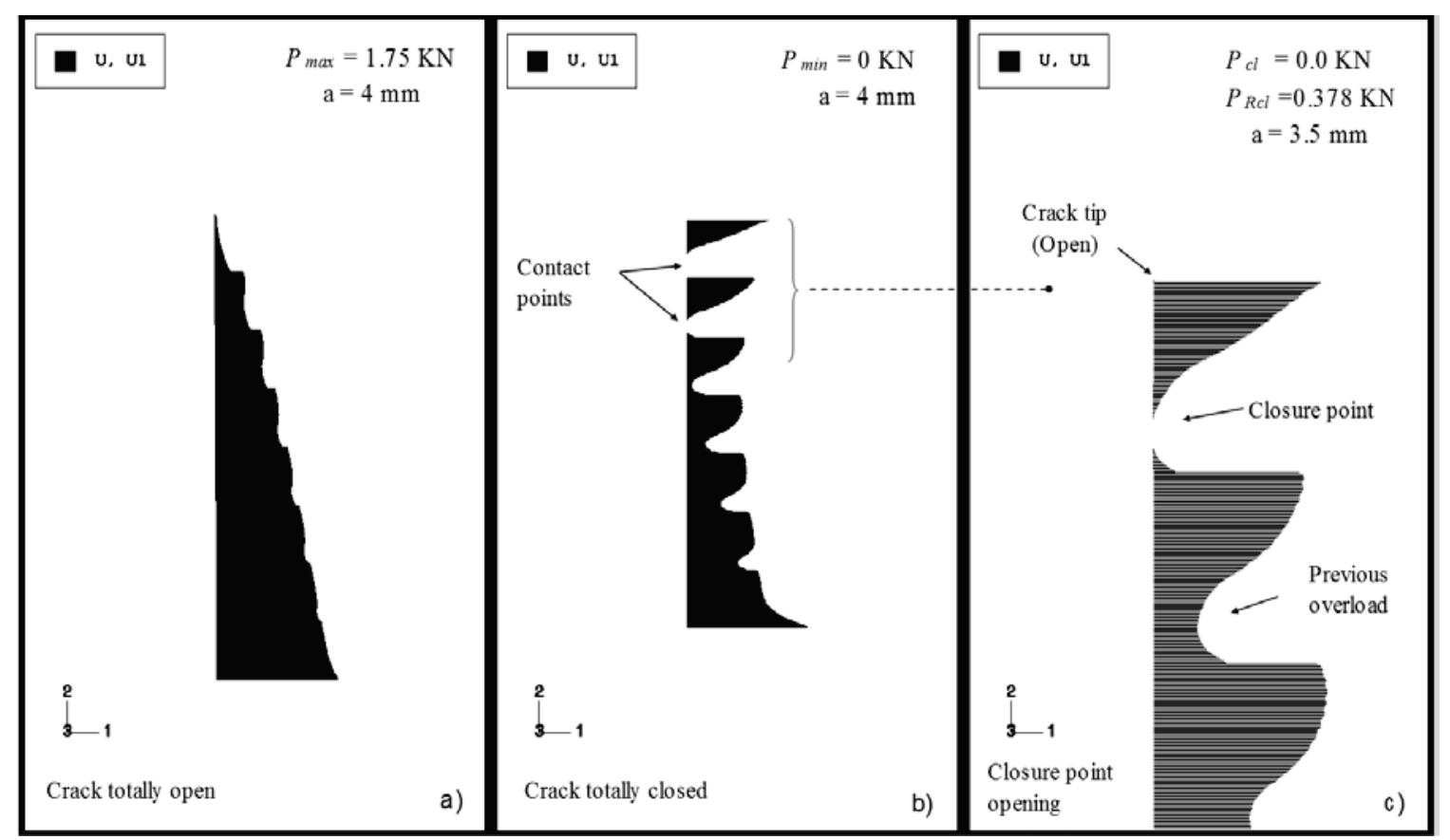

Fig 14. Contact profile for case $4 b$.

For case $4 \mathrm{c}$ (block overload/underload applied every $0.25 \mathrm{~mm}$ ) a similar pattern and similar behaviour is seen as in case $4 \mathrm{~b}$, see Fig. 15. Again the crack tip remains open during the next load cycle on the next node and when moving onto further nodes and load cycles the crack tip reverts back to closing first one node behind the crack tip. Cases 1c, 2c, and 3c behave similarly to 4c.

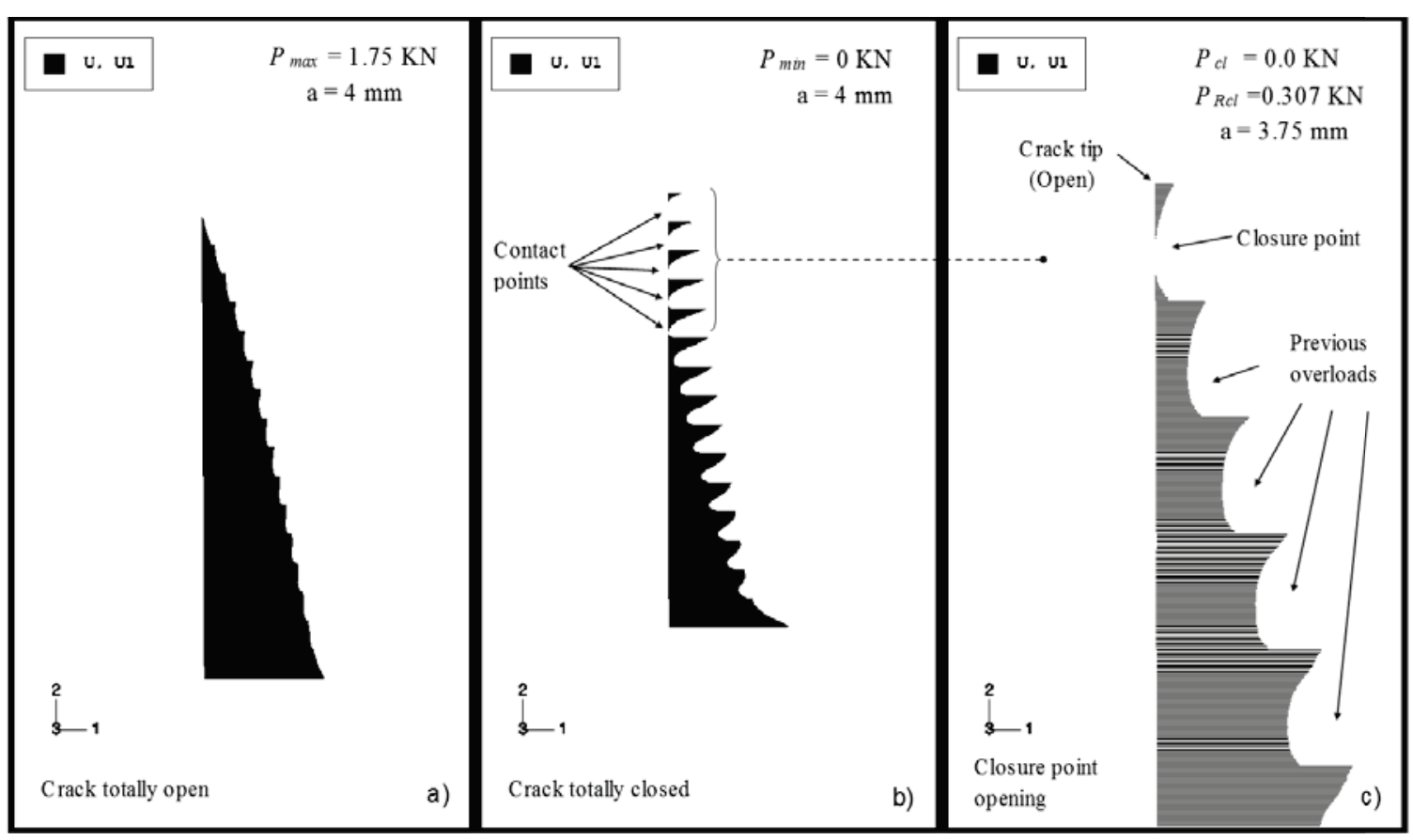

Fig 15. Contact profile for case 4c.

For the spectrum load case there is no obvious large plastic lumps along the crack length but the displacement curve is not smooth, see Fig. 16a, showing that plasticity has occurred. This is most apparent when the crack is unloaded, Fig. 16b, as there are various points along the crack length that have not closed. It can be seen in Fig. 16c 
that there are several points along the crack tip that are still in contact at the point that the node behind the crack tip opens. This situation suggests that a technique to measure opening and closure one node behind the crack tip might not produce accurate results when spectrum loading is applied.

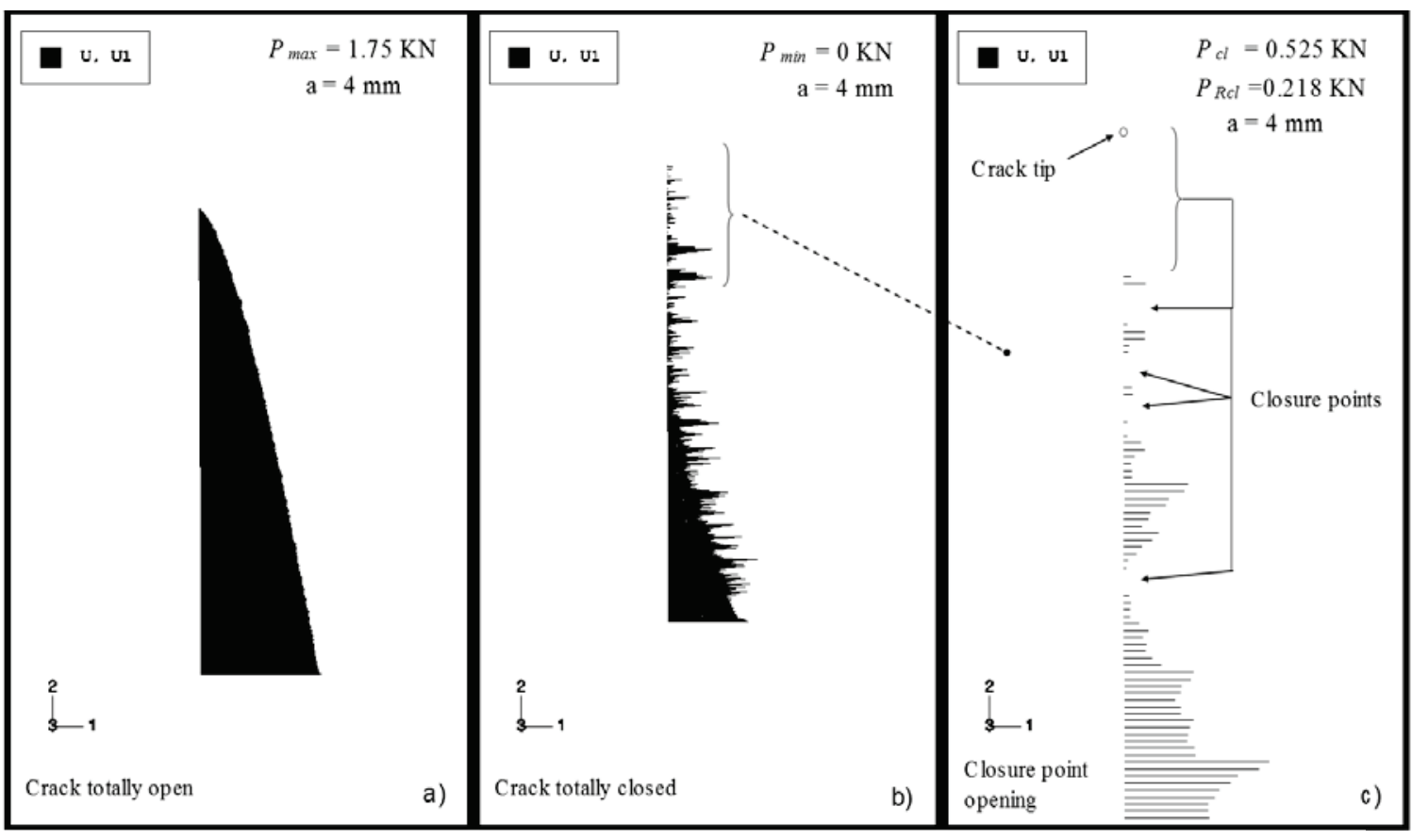

Fig 16. Contact profile for spectrum load case.

From this work it has been shown that the frequency of the application of overloads and overloads/underloads does have an effect on the position and load at which crack opening and closure occurs (when using isotropic hardening with cyclic hardening material properties in ABAQUS).

\subsection{Material Models}

Although cyclic properties were used in the material model, which has been shown to give improved results over elastic perfect plastic properties (3), the assumption of using isotropic hardening produced an over prediction on the $d a / d N$ retardation. This was particularly evident when overloads were applied with higher frequency, as in cases $1 \mathrm{~b}$ and $1 \mathrm{c}$, where overloads were applied at 0.5 and $0.25 \mathrm{~mm}$ respectively. Also it was found that using isotropic hardening properties produces bigger amplitudes for the opening stresses when block overloads were applied at a distance shorter than the overload interaction period. Borrego et. al. 6082 have incorporated both isotropic and kinematic hardening behaviour using a mixed hardening rule for some of their models $(34,59)$. For this reason a general material model consisting of a non-linear kinematic hardening and isotropic hardening components as given in Eq. (4) was used in a few simulations to see what effect it may have.

$$
d \alpha=C \frac{1}{\sigma^{o}}(\sigma-\alpha) d \bar{\varepsilon}^{p l}-\gamma \alpha d \bar{\varepsilon}^{p l}
$$


The non-linear isotropic/kinematic hardening model can provide more accurate results in many cases involving cyclic loading, however ABAQUS (43) specifies the following two limitations:

Firstly, the isotropic hardening is the same at all strain ranges. Physical observations, however, indicate that the amount of isotropic hardening depends on the magnitude of the strain range. Furthermore, if the specimen is cycled at two strain ranges, one followed by the other, the deformation in the first cycle affects the isotropic hardening in the second cycle. Thus, the model is only a coarse approximation of actual cyclic behaviour.

Secondly, the same cyclic hardening behaviour is predicted for proportional and nonproportional load cycles. Physical observations indicate that the cyclic hardening behaviour of materials subjected to non-proportional loading may be very different from uniaxial behaviour at similar strain amplitude.

Because of the previous limitations, the complexity of the material hardening calibration and the scatter in the material properties, it was decided to employ the linear kinematic hardening model (Eq. (5)), which is only the first part of the nonlinear isotropic/kinematic hardening model showed in Eq. (4). This model is known as the linear Ziegler hardening law.

$$
d \alpha=C \frac{1}{\sigma^{o}}(\sigma-\alpha) d \bar{\varepsilon}^{p l}
$$

were $d \bar{\varepsilon}^{p l}$ is the equivalent plastic strain rate, $\alpha$ is the back stress, $\sigma^{o}$ is the equivalent stress defining the size of the yield surface at zero plastic strain $\left.\sigma\right|_{o}$, and $C$ is the kinematic hardening modulus obtained as shown in Eq. (6).

$$
C=\frac{\sigma-\left.\sigma\right|_{o}}{\varepsilon^{p l}}
$$

There is an expectation of anisotropic behaviour at the crack tip when subjected to overloads, due to the high strain values generated, but when utilising the non-linear isotropic/kinematic option within ABAQUS standard (43) the only yield criterion available is the von Mises criterion. Using this material model the results shown in Fig. 17 were obtained for Case 3c. Fig. 18 shows the crack growth predictions using the previously presented isotropic hardening model in comparison with the same experimental results as shown in Fig. 17. Contrasting the results it can be seen that the linear kinematic hardening model is producing a better match to the experimental crack growth values, although both models are over predicting the crack growth for this specimen. Similar results were also obtained when comparing the hardening model FE crack growth results with other specimens tested. This seems to indicate that the crack growth is strongly influenced by the hardening model when variable amplitude loading is applied, especially when the frequency of overloads is high. 


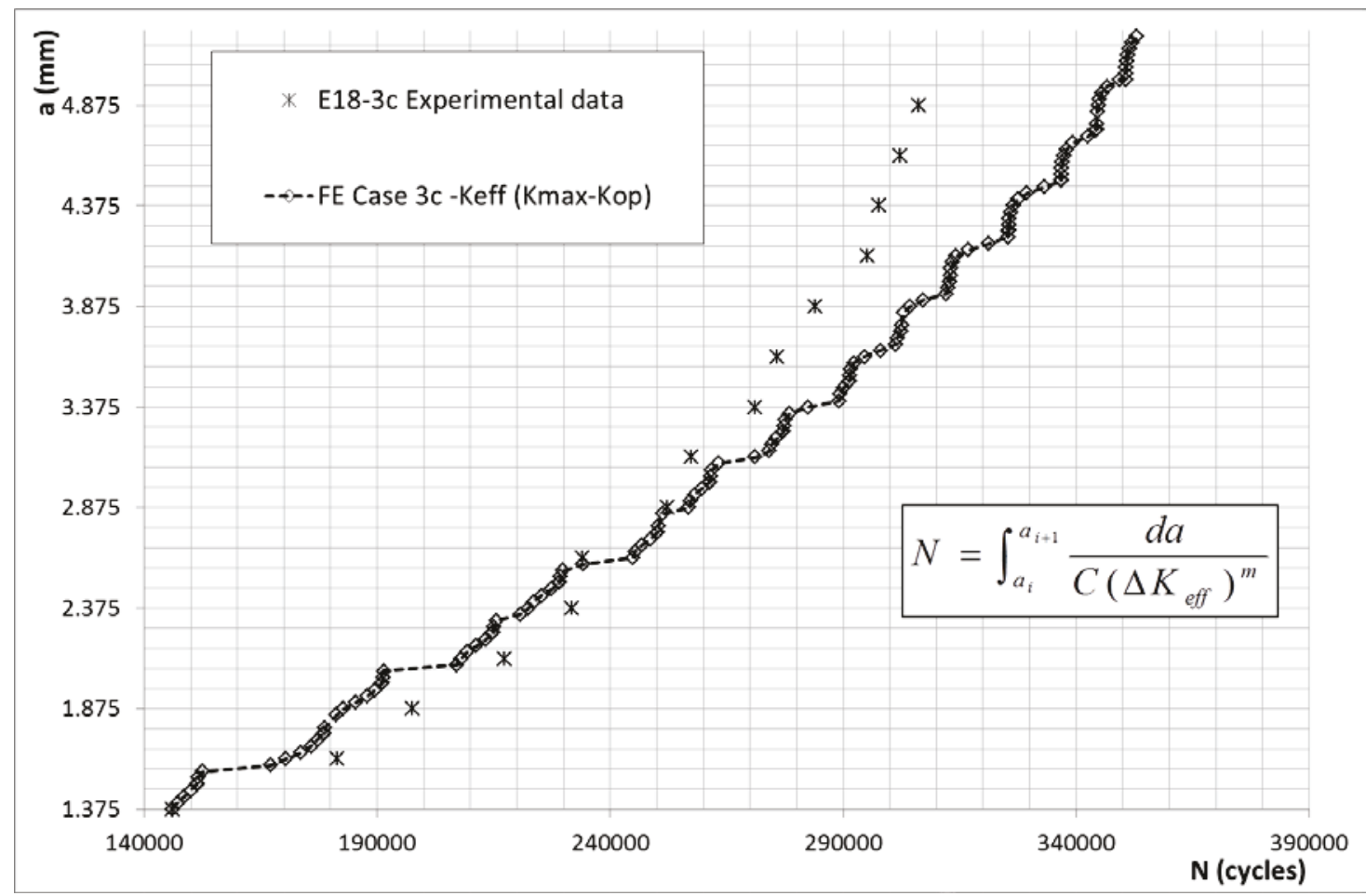

Fig 17. Case $3 \mathrm{c}, d a / d N$ comparison of experimental versus FE using kinematic hardening rule.

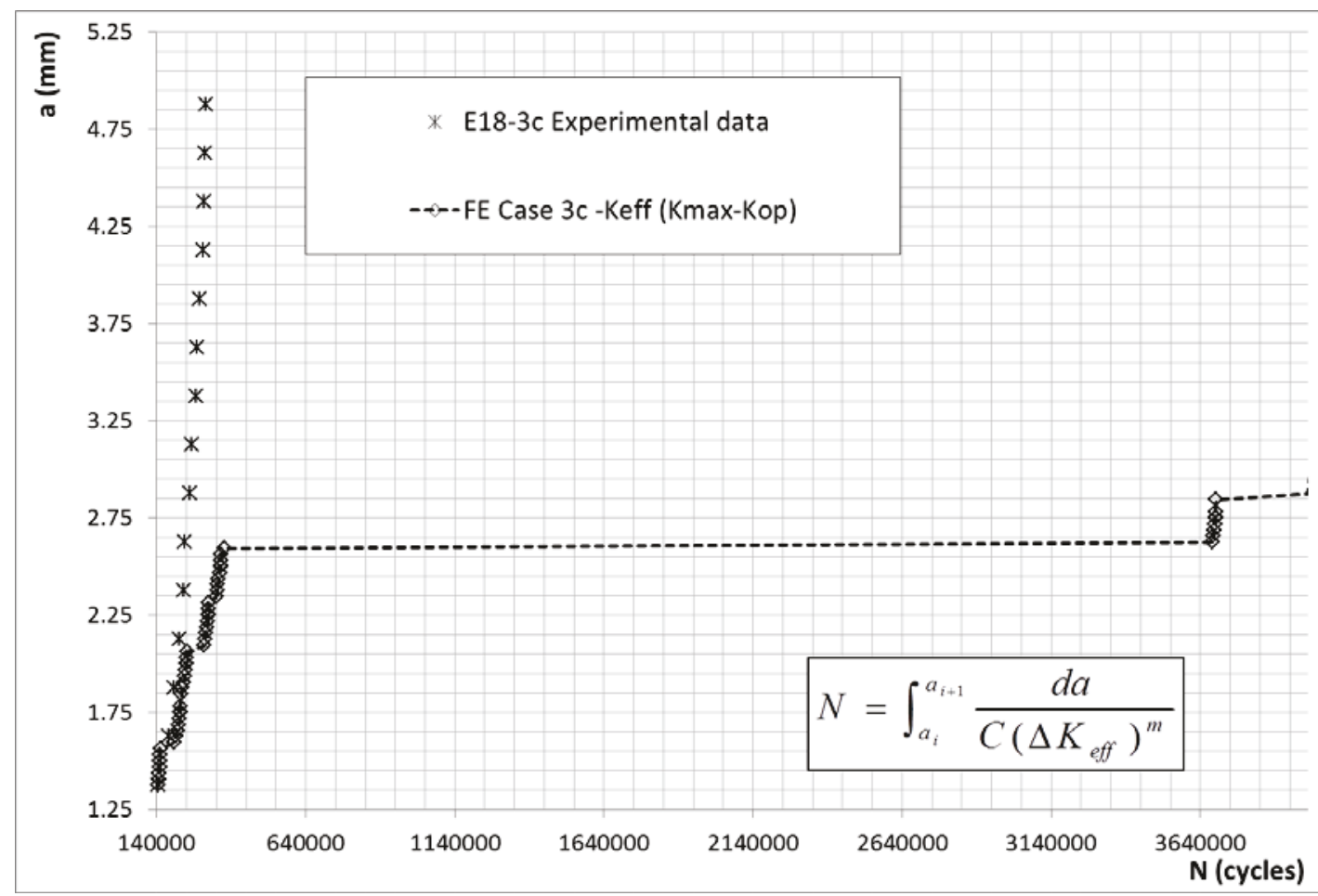

Fig 18. Case $3 \mathrm{c}, d a / d N$ comparison of experimental versus FE using isotropic hardening rule.

As can be seen in Fig. 19 the use of isotropic hardening gives much higher opening stresses (and closure stresses). This may be one reason that the closure results obtained numerically, shown in Table 2, do not match the experimental results, particularly for cases of block overloads where the cyclic behaviour of the material will be more influential. 


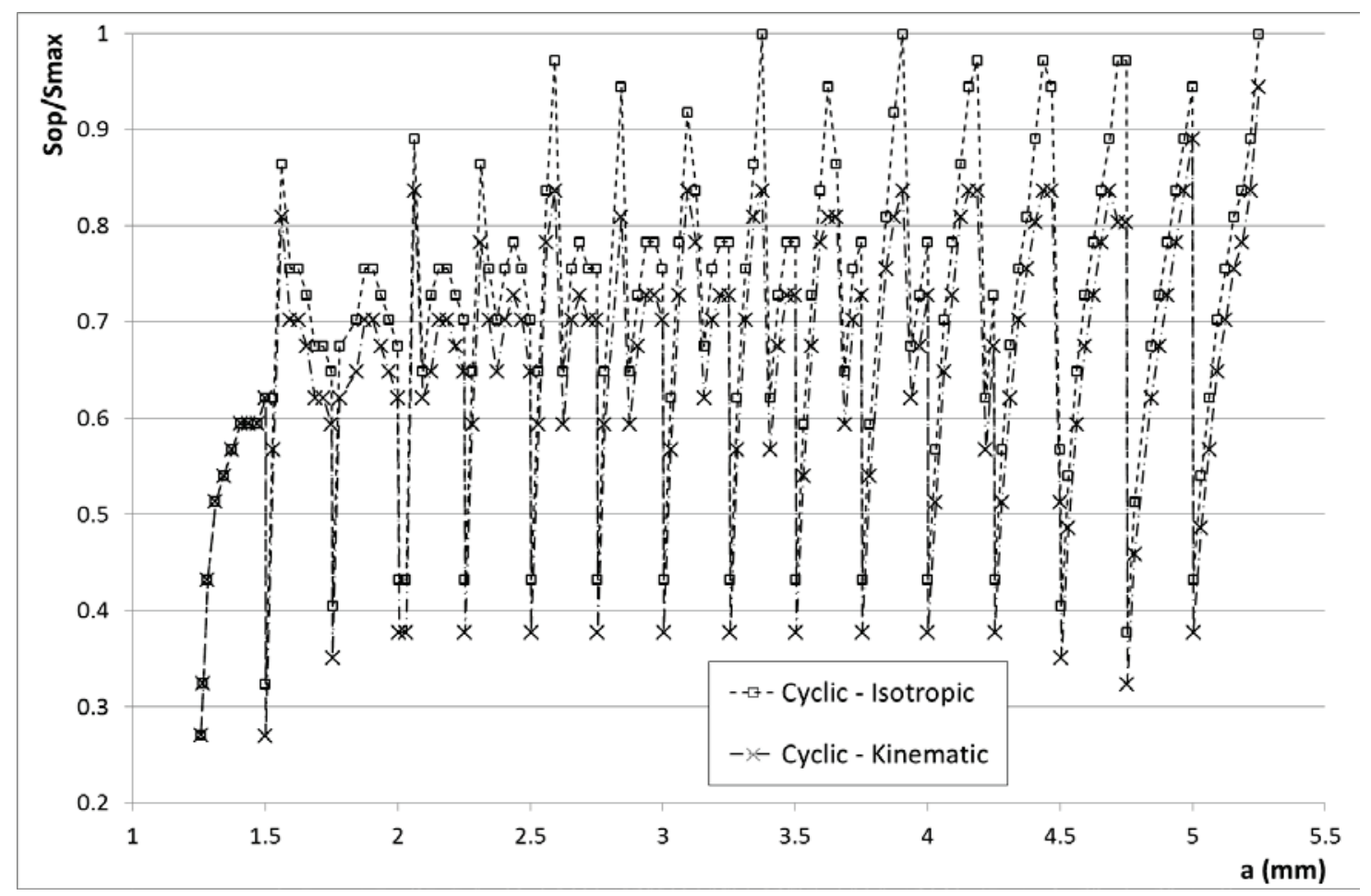

Fig 19. Kinematic and isotropic hardening rule comparison.

\subsection{Conclusions}

In this research the effect of variable amplitude loading on fatigue crack growth rate was studied in order to enhance the understanding of crack advance under variable loading conditions. The main conclusions are presented in the following paragraphs.

The ability of the model to cope with spectrum loading was tested using a quasirandom loading case. This demonstrated the capability of the model to deal with spectrum loading for long crack lengths. The model took 20 hours to simulate $4 \mathrm{~mm}$ of crack growth (Pentium 4, 1 GB Ram, 3.0 GHz.) showing that the model could be used for more realistic cases with the increasing computational power that is now available.

The numerical simulation carried out in this research was supported by experimental observations. Good agreement was obtained in terms of the delay distances before steady state crack growth continued $(\sim 0.65 \mathrm{~mm})$.

An investigation of the point at which closure occurred showed for overloads applied within the previous plastic wake (overload intervals $0.5 \mathrm{~mm}$ and $0.25 \mathrm{~mm}$ ) that the position of crack closure moved back from the crack tip temporarily. Once the crack was grown past the overload position the opening position returned to being one node behind the crack tip. For spectrum loading this could have a considerable influence on results. Although this effect will cause an error in terms of measuring the crack closure it does not account for the difference in numerical and experimental results discussed in the next paragraph.

The results for crack growth (and therefore crack opening and closure loads) were comparable for the case of single overloads but for overloads carried out more 
regularly, lower interval distances, there was a significant mismatch. Crack growth dropped initially when the overload interval was reduced to $0.5 \mathrm{~mm}$ for both numerical and experimental results but as the overload interval reduced further to 0.25 $\mathrm{mm}$ the experimental crack growth rose slightly whilst the numerical crack growth reduced further. It is clear that as the interval distance decreases to $0.5 \mathrm{~mm}$ the plastic zone generated becomes larger than the interval distance. This means there is always a plastic wake behind the crack which increases the crack opening and closing loads, which reduces crack growth. The effect of reducing the interval distance further is not obvious as the crack already has a continuous plastic wake. Experimentally decreasing the interval distance to $0.25 \mathrm{~mm}$ did not have an additional effect on crack growth rate and there are several explanations that might account for the numerical model not matching this result as discussed next.

It was found that when applying block overloads at a single node the da/dN was not as good as obtained when the overloads were applied at consecutive nodes. In reality as each overload is applied the crack advances. It was predicted analytically using the Paris equation (39) that each overload would cause a crack increase of $1 \mu \mathrm{m}$. This means that the plasticity generated by the block overloads would spread over $5 \mu \mathrm{m}$. When applying the overloads at successive nodes $(3.90625 \mu \mathrm{m})$ the prediction of $\mathrm{da} / \mathrm{dN}$ experimentally and numerically agreed well with a slight under prediction numerically for case $3 \mathrm{~b}$. Ideally the overloads should be applied at $1 \mu \mathrm{m}$ intervals which should bring the numerical results more in line with those obtained experimentally.

The main results presented have been based on numerical models incorporating isotropic hardening, which has been shown to give improved results over using elastic perfect plastic properties (3). Due to the mismatch in crack growth predictions it was decided in this work to investigate the effect of kinematic cyclic properties for some of the cases. It was found that cyclic hardening material properties coupled with kinematic hardening gave better results when comparing the numerical and experimental results. This effect is less obvious in constant amplitude loading as the Paris equation constants (39) can account for the difference, but this is not the case for variable amplitude loading.

The previous conclusion has some significance when considering the load cycle on which to release the node. In this work a load cycle was applied to establish the correct state of plasticity around the current node (in reality it would have grown to this point but in the model it jumps to this point through the previous node release) and a second load cycle was applied to measure the opening and closure loads. Other authors have used one cycle or up to four cycles. From the results obtained it would seem that if too many cycles are applied then excessive plasticity would be induced creating higher opening and closure loads than occur in reality. The reason this may not have been picked up before is that not many authors have used cyclic hardening and kinematic hardening and therefore the true effects of applying repeat cycles may not have been observed.

In real engineering components the material thickness is likely to be much larger than used by the authors experimentally (2) and numerically (3). This would lead to plane strain conditions in the middle of the component at the crack tip. Although this is true, at the surface of the component plane stress conditions will still dominate (34) making 
the application of the work relevant through analysing and modelling the surface displacements and stresses of real components.

In summary the numerical models showed some good correlation for single overloads and followed the general trend in terms of increased plasticity reducing crack growth rate. The crack growth rates for cases where overloads where applied at shorter intervals was though severally underestimated. The reasons for this are likely to be due to use of isotropic cyclic hardening material properties over kinematic cyclic hardening properties and the application of block overloads on a single node rather than spreading the load application over several nodes.

\section{ACKNOWLEGMENTS}

The authors would like to thank CONACYT, Mexico, for supporting the work through the provision of a PhD scholarship (Ref: 195606)

\section{REFRENCES}

1. Aguilar-Espinosa AA. Effect of variable amplitude loading on fatigue crack growth rate [electronic resource]. Oxford: Oxford Brookes University; 2009.

2. Aguilar-Espinosa AA, Fellows NA, Durodola JF. Experimental measurement of crack opening and closure loads for 6082-T6 aluminium subjected to periodic single and block overloads and underloads. International Journal of Fatigue. 2013;47:71-82.

3. Aguilar Espinosa AA, Fellows NA, Durodola JF, Fellows LJ. Development of numerical model for the determination of crack opening and closure loads, for long cracks. Fatigue \& Fracture of Engineering Materials \& Structures. 2017;40(4):571-85. 4. Suresh S. Micromechanisms of fatigue crack growth retardation following overloads. Engineering Fracture Mechanics. 1983;18(3):577-93.

5. Fleck NA. Fatigue crack growth due to periodic underloads and overloads. Acta Metallurgica. 1985;33(7):1339-54.

6. Geary W. A review of some aspects of fatigue crack growth under variable amplitute loading. International Journal of Fatigue. 1992;14(6):377-86.

7. Sadananda K, Vasudevan AK, Holtz RL, Lee EU. Analysis of overload effects and related phenomena. International Journal of Fatigue. 1999;21, Supplement 1:S233-S46.

8. Shorupa M. Load interaction effects during fatigue crack growth under variable amplitude loading - A literature review. Part I: Empirical trends (vol 21, pg 987, 1998). Fatigue \& Fracture of Engineering Materials \& Structures. 1999;22(10):926-.

9. Skorupa M. Load interaction effects during fatigue crack growth under variable amplitude loading - a literature review. Part II: qualitative interpretation. Fatigue \& Fracture of Engineering Materials \& Structures. 1999;22(10):905-26.

10. Pippan R, Hohenwarter A. Fatigue crack closure: a review of the physical phenomena. Fatigue \& Fracture of Engineering Materials \& Structures. 2017;40(4):471-95.

11. Bannantine JA, Comer JJ, Handrock JL. Fundamentals of metal fatigue analysis. Englewood Cliffs, N.J.: Prentice Hall; 1990. xiii, 273 p. p.

12. Elber W. Fatigue crack closure under cyclic tension. Engineering Fracture Mechanics. 1970;2:37-45. 
13. Elber W. The significance of fatigue crack closure. Damage Tolerance in Aircraft Sructures. American Society of Testing Materials; 1971. p. 230-42.

14. Newman JC. A finite element analysis of fatigue crack closure, Mechanics of crack growth. American Society of Testing Materials. 1976;STP 590:281-301.

15. Schijve J. Observations on the Prediction of Fatigue Crack Growth Propagation Under Variable-Amplitude Loading. American Society of Testing Materials; 1976. p. 56-80.

16. Ogura K, Ohji K. FEM analysis of crack closure and delay effect in fatigue crack growth under variable amplitude loading. Engineering Fracture Mechanics. 1977;9(2):471-80.

17. De Koning AU. A Simple Crack Closure Model for Prediction of Fatigue Crack Growth Rates under Variable Amplitude Loading. 1981;STP 743.

18. Fleck NA. An investigation of fatigue crack closure. Cambridge: University of Cambridge; 1983.

19. Ibrahim FK, Thompson JC, Topper TH. A study of the effect of mechanical variables on fatigue crack closure and propagation. International Journal of Fatigue. $1986 ; 8(3): 135-42$.

20. McClung RC, Sehitoglu H. On the finite-element analysis of fatigue crack closure .1. Basic modeling issues. Engineering Fracture Mechanics. 1989;33(2):23752.

21. Padmadinata UH. Investigation of crack-closure prediction models for fatigue in aluminum alloy sheet under flight-simulation loading. Delft, Netherlands: TUDelft; 1990.

22. Zhang X, Chan ASL, Davies GAO. Numerical simulation of fatigue crack growth under complex loading sequences. Engineering Fracture Mechanics. 1992;42(2):305-21.

23. Nowell. A boundary element model of plasticity-induced fatigue crack closure. Fatigue \& Fracture of Engineering Materials \& Structures. 1998;21(7):85771.

24. Fellows LJ. Fatigue crack growth under variable stress ratios and complex load history. Oxford, UK: University of Oxford; 1999.

25. Wei LW, James MN. A study of fatigue crack closure in polycarbonate CT specimens. Engineering Fracture Mechanics. 2000;66(3):223-42.

26. Khalil M. Effect of fatigue loading spectra on crack opening stress and crack shape development. Ontario, Canada: Waterloo University; 2002.

27. Solanki K, Daniewicz SR, Newman JC. Finite element analysis of plasticityinduced fatigue crack closure: an overview. Engineering Fracture Mechanics. 2004;71(2):149-71.

28. Khalil M, Topper TH. Prediction of crack-opening stress levels for 1045 asreceived steel under service loading spectra. International Journal of Fatigue. 2003;25(2):149-57.

29. Ohji K, Ogura K, Ohkubo Y. Cyclic analysis of a propagating crack and its correlation with fatigue crack growth. Engineering Fracture Mechanics. 1975;7(3):457-63.

30. Newman JC. Finite element analysis of crack growth under monotonic and cyclic loading. American Society of Testing Materials; 1977. p. 56-80.

31. Nakagaki M, Atluri SN. atigue Crack Closure Effect and Delay Effects under mode I Spectrum Loading: an efficient Elasto-Plastic Analysis Procedure. FFEMS. 1979;1:421-9. 
32. Blom AF, Holm DK. An experimental and numerical study of crack closure. Engineering Fracture Mechanics. 1985;22(6):997-1011.

33. Fleck NA. Finite-element analysis of plasticity-induced crack closure under plane-strain conditions. Engineering Fracture Mechanics. 1986;25(4):441-9.

34. Borrego LP, Antunes FV, Costa JD, Ferreira JM. Numerical simulation of plasticity induced crack closure under overloads and high-low blocks. Engineering Fracture Mechanics. 2012;95:57-71.

35. Singh KD, Khor KH, Sinclair I. Roughness- and plasticity-induced fatigue crack closure under single overloads: Finite element modelling. Acta Materialia. 2006;54(17):4393-403.

36. Standards B. Tensile testing of metallic materials. Method of test at ambient temperature. BSI; 2001.

37. Smithells CJ, Brandes EA, Brook GB. Smithells' metals reference book: Butterworth-Heinemann; 1992.

38. Borrego LP, Costa JM, Ferreira JM. Fatigue crack growth in thin aluminium alloy sheets under loading sequences with periodic overloads. Thin-Walled Structures. 2005;43(5):772-88.

39. Paris P, Erdogan F. A critical analysis of crack propagation rules. Journal of Basic Engineering. 1963;85:528-34.

40. Gonzalez-Herrera A, Zapatero J. Influence of minimum element size to determine crack closure stress by the finite element method. Engineering Fracture Mechanics. 2005;72(3):337-55.

41. Borrego LP, Abreu LM, Costa JM, Ferreira JM. Analysis of low cycle fatigue in AlMgSi aluminium alloys. Engineering Failure Analysis. 2004;11(5):715-25.

42. Borrego LP, Ferreira JM, Costa M. Partial crack closure under block loading. International Journal of Fatigue. 2008;30(10-11):1787-96.

43. ABAQUS/Standard User's Manual. Pawtucket, RI, USA: Hibbit, Karlsson \& Sorensen Inc; 2004.

44. Solanki K, Daniewicz SR, Newman JC. Finite element modeling of plasticityinduced crack closure with emphasis on geometry and mesh refinement effects. Engineering Fracture Mechanics. 2003;70(12):1475-89.

45. Urriolagoitia-Sosa G, Durodola JF, Lopez-Castro A, Fellows NA. A method for the simultaneous derivation of tensile and compressive behaviour of materials under Bauschinger effect using bend tests. Proceedings of the Institution of Mechanical Engineers, Part C: Journal of Mechanical Engineering Science. 2006;220(10):1509-18.

46. Noroozi AH, Glinka G, Lambert S. Prediction of fatigue crack growth under constant amplitude loading and a single overload based on elasto-plastic crack tip stresses and strains. Engineering Fracture Mechanics. 2008;75(2):188-206.

47. Wheeler OE. Spectrum Loading and Crack Growth. Journal of Basic Engineering. 1972;94(1):181-6.

48. Yuen BKC, Taheri F. Proposed modifications to the Wheeler retardation model for multiple overloading fatigue life prediction. International Journal of Fatigue. 2006;28(12):1803-19.

49. Kim JK, Shim DS. A statistical approach for predicting the crack retardation due to a single tensile overload. International Journal of Fatigue. 2003;25(4):335-42.

50. Croft MC, Jisrawi NM, Zhong Z, Holtz RL, Sadananda K, Skaritka JR, et al. Fatigue history and in-situ loading studies of the overload effect using high resolution X-ray strain profiling. International Journal of Fatigue. 2007;29(9-11):1726-36.

51. Schijve J. Fatigue of Structures and Materials: Springer Netherlands; 2008. 
52. Stephens RI, Chen DK, Hom BW. Fatigue Crack Growth with Negative Stress Ratio Following Single Overloads in 2024-T3 and 7075-T6 Aluminum Alloys. American Society of Testing Materials; 1976.

53. Guerra-Rosa L, Branco CM, Radon JC. Influence of Plastic Zone Size on Closure Phenomenon at Fatigue

Thresholds in Steels. Fatigue 84 - Proceedings of the 2nd International Fatigue Conference; Birmingham, UK1984.

54. Ohrloff N, Gysler A, Lutjering G. Fatigue crack propagation behavior under variable amplitude load. In: Petit J, Davidson DL, Suresh S, Rabbe P, editors. Fatigue Crack Growth Under Variable Amplitude Loading. Netherlands: Springer Netherlands; 1988. p. 24-34.

55. Robin C, Busch ML, Chergui M, Lieurade HP, Pluvinage G. Influence of series of tensile and compressive overloads on 316L crack growth. Fatigue crack growth under variable amplitude load In: Petit J, Davidson DL, Suresh S, Rabbe P, editors. Fatigue Crack Growth Under Variable Amplitude Loading. Netherlands: Springer Netherlands; 1988. p. 87-97.

56. Zhang S, Schulte K, Marissen R, Trautmann KH, Nowack H. A systematic fracture analysis for the evaluation of crack closure concept Fatigue crack growth under variable amplitude load. In: Petit J, Davidson DL, Suresh S, Rabbe P, editors. Fatigue Crack Growth Under Variable Amplitude Loading. Netherlands: Springer Netherlands; 1988. p. 24-34.

57. Dabayeh AA, Topper TH. Changes in crack-opening stress after underloads and overloads in 2024-T351 aluminium alloy. International Journal of Fatigue. 1995;17(4):261-9.

58. Shuter DM, Geary W. Some aspects of fatigue crack growth retardation behaviour following tensile overloads in a structural steel. Fatigue \& Fracture of Engineering Materials \& Structures. 1996;19(2-3):185-99.

59. Antunes FV, Borrego LFP, Costa JD, Ferreira JM. A numerical study of fatigue crack closure induced by plasticity. Fatigue \& Fracture of Engineering Materials \& Structures. 2004;27(9):825-35.

\section{List of Figures}

Fig 1. Specimen Test Configuration, $\mathrm{P}=1.75 \mathrm{k}$

Fig 2. Opening (a) and closure (b) stresses for overload applied at $3.25 \mathrm{~mm}$ along the crack length for all the cases $1,2,3$ and 4 . $R=0$.

Fig 3. Opening (a) and closure (b) stresses for single overload cases applied every $0.25 \mathrm{~mm}$ along the crack length for all the cases $1,2,3$ and 4. $R=0$.

Fig 4. Opening a), and closure b) stress response during periodic overload. $R=0$, mesh size $0.00390625 \mathrm{~mm}$.

Fig 5. Spectrum load case along $5.25 \mathrm{~mm}$ crack length. $\mathrm{R}=0, \Delta \mathrm{a}=000390625 \mathrm{~mm}$.

Fig 6. Opening a) and closure b) stress response during spectrum load. $R=0$, mesh size $0.00390625 \mathrm{~mm}$.

Fig 7. Experimental average values for $d a / d N$ behaviour for CA and VA loading $\left(R=0, P_{M A X}=1.75 \mathrm{kN}, P_{O}= \pm 3 \mathrm{kN}\right)$.

Fig 8. Numerical average values for $\mathrm{da} / \mathrm{dN}$ behaviour for $\mathrm{CA}$ and VA loading $(\mathrm{R}=0$, PMAX $=1.75 \mathrm{kN}, \mathrm{PO}= \pm 3 \mathrm{kN}$ ).

Fig 9. Experimental and numerical average values for $\mathrm{da} / \mathrm{dN}$ behaviour for $\mathrm{CA}$ and VA loading $(\mathrm{R}=0, \mathrm{PMAX}=1.75 \mathrm{kN}, \mathrm{PO}= \pm 3 \mathrm{kN})$.

Fig 10. Transition periods attributed to crack closure a) numerical results, b) experimental results. 
Fig 11. Crack growth rate for case 3a. Comparison between experimental results and FE simulation.

Fig 12. Plasticity recorded at the same node employing two different criteria to apply the block overloads.

Fig 13. Contact profile for case 4a.

Fig 14. Contact profile for case $4 b$.

Fig 15. Contact profile for case 4c.

Fig 16. Contact profile for spectrum load case.

Fig 17. Case $3 \mathrm{c}, \mathrm{da} / \mathrm{dN}$ comparison of experimental versus $\mathrm{FE}$ using kinematic hardening rule.

Fig 18. Case $3 \mathrm{c}, d a / d N$ comparison of experimental versus FE using isotropic hardening

Fig 19. Kinematic and isotropic hardening rule comparison.

List of Tables

Table 1 Mechanical properties of 6082-T6 aluminium alloy

Table 2 Experimental Load Cases

Table 3 Opening stress values at $2 \mathrm{~mm}$ crack length after the applied overload

Table 4 Opening stresses $S_{o p}$ at the point where maximum retardation occurred for all overload cases 